\title{
Progress in Lignin Hydrogels and Nanocomposites for Water
}

\section{Purification: Future Perspectives}

\author{
Sourbh Thakur ${ }^{\mathrm{a}}$, Penny P. Govender ${ }^{\mathrm{a}^{*}}$, Messai A. Mamo ${ }^{\mathrm{a}^{*}, \text { Sigitas Tamulevicius }^{\mathrm{b}}}$ \\ Yogendra Kumar Mishra ${ }^{c^{*}}$, Vijay Kumar Thakur ${ }^{d *}$ \\ ${ }^{a}$ Department of Applied Chemistry, University of Johannesburg, Doornfontein 2028, \\ Johannesburg, South Africa \\ ${ }^{b}$ Institute of Materials Science of Kaunas University of Technology, Barsausko 59, LT-51423 \\ Kaunas, Lithuania. \\ ${ }^{c}$ Functional Nanomaterials, Institute for Materials Science, Kiel University, Kaiserstrae 2, D- \\ 24143 Kiel, Germany. \\ ${ }^{d}$ Enhanced Composites and Structures Center, School of Aerospace, Transport and \\ Manufacturing, Cranfield University, Bedfordshire MK43 OAL, UK
}

\begin{abstract}
Lignin, one of the most abundant natural polymer after cellulose has attracted great attention in academia as well as in industry for miscellaneous applications. Lignin also exhibits very high potential as a renewable sustainable resource for galaxy of high value biochemicals. Due to typical structure of lignin, it can be converted into different type of useful products. From lignocellulose biorefinery prospective point of view, it can be regarded as an economic bio product and can also be used as filler in several polymers to form blend or composites. Recently lignin based hydrogels have shown excellent performance for removal of various pollutants from
\end{abstract}


water. The adsorption properties of lignin based hydrogels can further be improved by using the combination of nanomaterials and lignin that results in promising hydrogel nanocomposites. In nature, most abundant structures are formed by the combination of lignin, cellulose and hemicelluloses. So, in this article, we have attempted to comprehensively review the research work carried out in the direction of usage of lignin based hydrogel for removal of toxic pollutants including metal ions and dyes.

Keywords: Lignin; structure; hydrogel; nanocomposite; water treatment; metal ions; dyes. *Corresponding authors Email: vijay.kumar@cranfield.ac.uk, ykm@tf.uni-kiel.de, messaim@uj.ac.za, pennyg@uj.ac.za

\section{Introduction}

Hydrogels belongs to a category of soft matter comprising of polymeric cross-linked threedimensional structure [1,2]. The characteristics of hydrogels such as flexibility, elasticity and permeability are attributed to their high water absorption ability [3]. They shows both half liquidlike and half solid-like properties [4,5]. Three-dimensional structure of hydrogel is generally organized by (a) chemical cross linking and (b) physical cross linking [6,7]. Coordination bonds, electrostatic interaction, hydrogen bonding and hydrophobic interaction are responsible for the formation of physically cross-linked hydrogels. The aqueous solution of amphiphilic organic molecules [8] or inorganic nanoparticles [9] can produce hydrogel through supramolecular chemistry. Physically cross-linked hydrogels have sol-gel phase transition [10] on exposure to external stimuli [11,12]. On the other hand, change in external conditions such as pH [13], electric field [14], temperature [15,16] and ionic strength [5] leads to the volume phase 
transitions [17] in chemically cross linked hydrogels. These hydrogels exhibits permanent three dimensional networks. Because of these features, hydrogels have potential use in various applications such as superabsorbent, bio actuators, microfluidic devices, packaging materials catalyst supports and biomedical materials [18-26]. Super absorbent characteristics of hydrogels are attributed to their ability to absorb huge quantity of water, about 10-20 times as compared to their original molecular weight, after absorbing water hydrogel achieves a swollen sate [27,28]. On the other hand, Xerogels (an important class of gels) may be defined as hydrogels without water, dried hydrogels, water is removed from hydrogels network. While, aerogels exhibits the removal of water molecules from hydrogels network with no deformation of structure [29]. The diffusion process of hydrogel depends on their structure and the thermodynamic behavior of components used in the formation of hydrogel network [7]. The swelling capability of a hydrogel is linked to the porosity of network and porosity generally depends on (a) crosslinking density and (b) attraction between hydrogel and aqueous solution. The porosity of structure also permits the adsorption of pollutants from wastewater or water [30,31]. Water exists in different forms in the network of hydrogel. The presence of water in hydrogel can be divided into four types [32] as: (a) free water present in outer part that can be removed easily or easily extractable bulk water of hydrogel structure, (b) physically entrapped water, exist in interstices of network named interstitial water, (c) chemically attached bound water through functional groups and linked directly to network, it cannot be removed under normal conditions from hydrogel network, (d) semi bound water, neither free nor bound water, but exist in between these two type of water. DSC thermogram can be used to identify and characterize the water present in hydrogel [33]. The development of network of hydrogel depends on the kind and quantity of cross linker used in the formation of hydrogel. Different types of cross linkers are required for different 
applications [32]. Cross-linkers can be classified as (a) physical and (b) chemical cross-linkers. Physical cross linking includes hydrogen bonding, freeze thawing, thermo gelation and charge interactions [34-39]. Chemical cross linking in hydrogels may be due to the radical polymerization, high energy irradiation, enzymes and reaction of functional groups [40-44]. Insolubility of hydrogels is because of the presence of chemical and physical cross links. At equilibrium swelling state, dispersion and cohesive forces of hydrogel becomes equal $[32,45]$. Dipole-dipole, electrostatic and hydrophobic forces can contribute to cohesive forces, covalent bond is usually responsible for cohesive forces. Biopolymers based materials such as hydrogels and fibres are lighted topic and represent the most promising biorenewable materials for various applications [46-49]. Tunable and degradation characteristics are advantages of biopolymer based hydrogels. The use of lignin for different applications has been reported earlier and wellreviewed due to the inherent advantages of lignin [48] [50] [51-56]. So, in this article, we will primarily focus on the recent progress carried out in lignin based hydrogel material for water treatment.

\section{Lignin Structure}

In 1838, the structure of wood was first elucidated by Anselme Payen, French scientist [57]. He obtained a material by reacting wood with nitric acid which looks like thread called cellulose. There was substance enriched of carbon even after the extraction of cellulose. Anselme Payen used the better extraction process and successfully obtained a new encrusting substance named lignin [56]. It was found in 1890 that lignin did not belong to polysaccharides and cellulose and lignin were differing by methoxy groups [56]. Lignocellulosic biomass has attracted great attention because of its accessibility and lack of contest with supply of feed[58] [59] [60] [61] 
[62,63]. Lignocellulosic biomass made up of three components [64]: (a) cellulose, (b) hemicellulose and (c) lignin (Figure 1) [65] [66] [67] [68]. Study regarding lignin is still going on because of its specific characteristics.

Lignin is found in plant and most of the plant biomass can consist of 30\% of lignin [69]. In earth, after cellulose, lignin is most abundant aromatic natural complex polymer [52] [70] [71]. Strength, integrity and inflexibility [72] of plant cell are provided by binding of lignin with cellulose and hemicelluloses[73] [74] [75] as shown in Figure 2 (a). Several pre-treatment processes are used for the extraction of lignin from different lignocellulosic resources. Most of the currently used pre-treatment processes have been found to generate toxic compounds and inhibitors during the lignin processing (Figure 2b)

Amorphous lignin polymer has significant use in fluid flow, pathogen resistance and response to stress [76]. Such lignin-polysaccharides network helps in bio refining by cell walls. Monolignols-p-coumaryl, sinapyl and coniferyl alcohols [77,78] are the three phenylpropanoid from which lignin is derived giving p-hydroxyphenyl (H), syringyl (S) and guaicyl (G) units respectively. Generally, the linkages $\beta-\mathrm{O}-4{ }^{\prime}, \beta-5^{\prime}, \alpha-\mathrm{O}-4$ ', $4-\mathrm{O}-5^{\prime}, \beta-\beta^{\prime}$ exist in between the subunits, $\beta-1$ ' and 5-5' linkages also exist but in small amount. 0-5/95-100/0, 0-8/25-50/46-75 and 5-33/33-80/20-54 are the H/G/S ratio in softwood, hardwood and grasses respectively [79]. The structure of lignin can be best depicted by common empirical chemical formula. The common empirical chemical formula is based on $\mathrm{C}_{9}$ formula which represent the nine carbon atom molar ratio with respect to other elements, formula shows common repeating unit which are formed by monolignols. $\mathrm{C}_{9} \mathrm{H}_{7.92} \mathrm{O}_{2.40}\left(\mathrm{OCH}_{3}\right)_{0.92}$ and $\mathrm{C}_{9} \mathrm{H}_{7.49} \mathrm{O}_{2.53}\left(\mathrm{OCH}_{3}\right)_{1.39}$ [80] are the $\mathrm{C}_{9}$ formula of softwood and hardwood lignin respectively. The difference between softwood and hardwood is due to their different monolignols ratio. 
Freudenberg [81] (1965), Adler [82] (1977), Brunow et al. [83] (1998) and Gellerstedt [84] (2007) respectively developed structure for spruce (softwood) lignin and beech (hardwood) lignin structure was produced by Nimz [85] (1974). According to Adler [82] and Gellerstedt [84], models for structure of lignin can be represented in different ways. The structure of type 1 and type 2 lignin existing in plant was given by Gellerstedt el al. $[84,86]$. The weight/weight percentage $(\mathrm{w} / \mathrm{w} \%)$ of spruce lignin is 48 in type 1 whereas it is 40 in type $2[84,86]$. Glucomannan-lignin-xylan $(\mathrm{w} / \mathrm{w}=9: 9: 1)$ and xylan-lignin-glucomannan $(\mathrm{w} / \mathrm{w}=2: 3: 1)$ are the complexes contained type 1 lignin and type 2 lignin respectively. Type 1 lignin is attached directly to cellulose strands via hydrogen bridges. The repeating units of type 1 lignin are connected by the distinct linkages. Type 2 lignin is situated across the cellulose fibrils enclosed in type 1 lignin. Generally, ether bond linkage i.e. $\beta-\mathrm{O}-4^{\prime}$ exist in between the repeating units for both softwood and hardwood lignin. About 50\% and 60\% [53,87] of $\beta-\mathrm{O}-4^{\prime}$ ether bonds can be found in softwood and hardwood lignin respectively.

\section{Lignin Hydrogels for Water Purification}

Lignin based hydrogels have been reported to be used in water treatment for removing different pollutant [88-102] from water or wastewater (Table 1). Recently, Li et al. synthesized highly porous lignosulfonate based graphene hydrogel through hydrothermal method for lead ion $\left(\mathrm{Pb}^{2+}\right)$ [88] adsorption from water. A very high adsorption capacity i.e. $1210 \mathrm{mg} \mathrm{g}^{-1}$ was reported for removal of $\mathrm{Pb}^{2+}$. The dispersion of lignosulfonate/graphene oxide aqueous solution comprising 1 $\mathrm{mg} \mathrm{mL} L^{-1}$ graphene oxide and $0.050 \mathrm{mg} \mathrm{mL}^{-1}$ lignosulfonate before and after the treatment by hydrothermal is demonstrated in Figure 3a. 
The developed lignosulfonate based graphene hydrogel having mass $5.4 \pm 0.2 \mathrm{mg}$ with $98.6 \%$ water was thin and intense sufficient to tolerate about $100 \mathrm{~g}$ weight by three hydrogels. (Figure 3b and c). On application of tension, some deformations were detected which were disappeared shortly. Highly porous three dimensional structure of lignosulfonate based graphene hydrogel was confirmed by SEM images as represented in Figure 3d-f. The variable pore sizes (nanometers to micrometers) of this hydrogel were observed. High specific surface area of 459.3 $\mathrm{m}^{2} \mathrm{~g}^{-1}$ was provided by the micro and mesoporosity while macroporosity insured approachability to such surface. Three dimensional porous structures were developed by hydrophilic aerated groups and pi-pi interaction between the sheets of grapheme (Figure 3).

Dual role i.e. dispersant and functional agents were played by the lignosulfonate in the formation of hydrogel. Hydrothermal process for the synthesis of this hydrogel occurred through the aggregation of graphene oxide sheets due to pi-pi interactions whereas lignosulfonate did not undergo any change in its structure on hydrothermal treatment. The homogeneous dispersion was given by negatively charged lignosulfonate to graphene oxide sheets via electrostatic repulsion. The interaction between lignosulfonate and reduced graphene oxide sheets was explained by noncovalent interactions such as pi-pi conjugation and hydrogen bonding as shown in Figure 4. Importantly, lignosulfonate based graphene hydrogel was fabricated in a column-packed device (Figure 5a) for the fast $\mathrm{Pb}^{2+}$ removal from aqueous solution with excellent adsorption capacity i.e. $308 \mathrm{mg} \mathrm{g}^{-1}$ in $40 \mathrm{~min}$, which was $1210 \mathrm{mg} \mathrm{g}^{-1}$ in $240 \mathrm{~min}$ for conventional shaking adsorption method. The column-packed adsorption gave effective way to use the interior pores of lignosulfonate based graphene hydrogel for the adsorption of $\mathrm{Pb}^{2+}$ ions. Adsorption experiments were performed for $\mathrm{Pb}^{2+}$ ions by using batch method with $40 \mathrm{ml} \mathrm{Pb}^{2+}$ aqueous solution, $400 \mathrm{mg}$ $\mathrm{mL}^{-1}$ of $\mathrm{Pb}^{2+}$ initial concentration. The graph between adsorption capacities and contact times are 
given in Figure 5b. Moreover, this hydrogel showed excellent reusable and regeneration study after many adsorption-desorption (Figure 5c). The 90\% and 82\% adsorption capacities were preserved after five and ten cycles respectively.

In another work, adsorption capacity of $235 \mathrm{mg} \mathrm{g}^{-1}$ was reported for adsorption of $\mathrm{Pb}^{2+}$ by using lignin grafted polyacrylic hydrogel [89]. Closed honeycomb cell morphology was obtained for polyacrylic, while porous and rough surface with enhanced surface was observed by grafting of polyacrylic acid onto lignin. The mechanisn of $\mathrm{Pb}^{2+}$ adsorption was explained on the basis of ion exchange or electrostatic attraction [89].

Yin et al. synthesized cellulose-lignin composite hydrogel using ultrasonic irradiation for the removal of $\mathrm{Pb}^{2+}$ from water [90]. The optimum adsorption capacity of $786.16 \mathrm{mg} \mathrm{g}^{-1}$ was reported in this hydrogel for $\mathrm{Pb}^{2+}$ adsorption. Kwak et al used silk sericin and lignin blend as adsorbent from agricultural by-products for the effective removal of hexavalent chromium $\left(\mathrm{Cr}^{6+}\right)$ with adsorption capacity $139.86 \mathrm{mg} \mathrm{g}^{-1}$ [91]. Dax et al. developed hemicelluloses based hydrogels for the application of removal of pollutants such as arsenic and chromium ions from aqueous solution [92]. Two molar mass molar of 7.1 and $28 \mathrm{kDa}$ of O-acetyl galactoglucomannan macromonomers (GGM) with methacrylate groups (MA) were applied as crosslinker in the formation of hydrogels utilizing monomer of [2(methacryloyloxy)ethyl]trimethylammonium chloride. The reaction occurred between O-acetyl galactoglucomannan and glycidyl methacrylate to form O-acetyl galactoglucomannan macromonomers through transesterification. Hydrogels with different GGM were represented as GGM5-MA $\left(\mathrm{M}_{\mathrm{n}}=4.7 \mathrm{kDa}\right)$ and GGM22-MA $\left(\mathrm{M}_{\mathrm{n}}=21.5 \mathrm{kDa}\right)$. It was found that swelling capacity for GGM5-MA was 3.7 times higher as comparison to GGM22-MA. The swelling capacity was visualized in simple way by showing one radical and one polymer chain arising in 
the reaction system (Figure 6). Polymer chain was attached to one GGM-MA (Figure 6, (1)), growth began and attached to second GGM-MA. Then, third GGM-MA chain came in contact with active polymer chain (Figure 6, (2)). The flexibility of three chains was still maintained for both hydrogels (GGM5-MA and GGM22-MA). The difference in swelling potential was observed when three GGM-MA chains were merged (Figure 6, (3)). The swelling capacity of hydrogel was decreased at this stage and it was difficult for chains to depart. The swelling ability was reduced due to the formation of strong crosslinked network in hydrogel utilizing GGM22MA as crosslinker as highlighted in red (Figure 6(4)). Initially at time 0, brownish color was shown by dried synthetic polymer, which was changed to transparent after swelling in $22 \mathrm{~h}$. Figure 7 shows the SEM images of freeze dried GGM based hydrogel at three magnifications. The unevenly distributed particles having smooth surface was seen at low magnification (Figure 7a). The porous surface was observed after drying process (Figure 7b). At high magnification, extended surface of this hydrogel was found (Figure 7c). The potential of the newly synthesized hydrogels was investigated for wastewater treatment by carrying out different sorption experiments at $\mathrm{pH}$ 9. Figure 8 demonstrates the sorption $(\mathrm{S})$ of the developed hydrogels as a function of the swelling rate (Q). It was concluded from this study that the hydrogels in general exhibited the good sorption capacities for both arsenates/ chromates as the capacities were found more at higher swelling rate.

A lignin hydrogel based on bentonite/sodium lignosulfonate/acrylamide/maleic anhydride (BLPAMA) was prepared for the adsorption of lead ions $\left(\mathrm{Pb}^{2+}\right)$ and exhibited high adsorption capacity of $322.70 \mathrm{mg} \mathrm{g}^{-1}$ [93]. In this work, the behavior of the synthesized hydrogels was studied as a function of different reaction parameters such as initial $\mathrm{pH}$, contact time, adsorbent dosage, temperature, concentration of $\mathrm{Pb}^{2+}$, and additive electrolyte. Figure 9 shows the 
mechanism for the synthesis of BLPAMA hydrogel. Different characterization techniques such as FTIR, TGA, XPS and SEM were used for detailed elucidation of the BLPAMA hydrogel adsorption mechanisms on a micro level. Figure $\mathbf{1 0}$ shows the comparative surface morphologies of both the BLPAMA and $\mathrm{Pb}^{+}$loaded hydrogel (BLPAMA) and significant changes were observed for both the hydrogels confirming the successful adsorption of metal ions. These results were further supported by the XPS spectra and were also in agreement with the experimental results of the effect of initial $\mathrm{pH} /$ the ionic strength (Figure 11). The mechanism of adsorption of lead ions onto this hydrogel was explained primarily by ion exchange and chelation. In another study, the effect of lignin on the adsorption capacity of starch/acryl amide-based hydrogels for the adsorption of $\mathrm{Cu}^{2+}$ and $\mathrm{Ni}^{2+}$ was investigated [94]. In this work interpenetrating polymer network (IPN) were created for the adsorption of metal ions. Scanning electron microscopy (SEM) and infrared spectroscopy was employed to investigate the morphology and functional groups incorporated onto the surface. Fick's law was further used to study the behavior of hydrogels in water. All the IPN based hydrogels were found to show Fickean water transport mechanism and were proposed to have a high potential to develop metal ion-collector membranes [94]. Grafting of acrylic acid monomer on lignosulfonate backbone was carried out using N,N'-methylene-bis-acrylamide and laccase/t-BHP(tert-butyl hydroperoxide) as cross linker and initiator respectively [95]. Figure 12 shows the proposed schematic for synthesis of LS-g-AA hydrogels. The successful grafting of the monomer was confirmed using FTIR (Figure 13).

Lignosulfonate-g-acrylic acid showed high methylene blue dye adsorption capacity of $2013 \mathrm{mg}$ $\mathrm{g}^{-1}$. The effect of $\mathrm{pH}$, time and methylene blue dye concentration on adsorption capacity was studied. Excellent reusability was shown by lignosulfonate grafted acrylic acid hydrogel with 
adsorption capacity 1757 and $1681 \mathrm{mg} \mathrm{g}^{-1}$ for 3 and 4 cycle respectively. The photograph of lignosulfonate grafted acrylic acid hydrogel is shown in Figure 14. Transparency of lignosulfonate grafted acrylic acid hydrogel was interrupted by the formation of bubbles, which were due to entraining air during stirring of reaction. Tang et al. have reported their studies on the preparation of lignin sulfonate-based mesoporous materials (LSMMs) for adsorbing malachite green from aqueous solution [96]. Copolymer adsorbent was synthesized by grafting of acrylic acid and acrylamide onto backbone of lignin sulfonate for the application of malachite green dye removal from water [96]. Figure 15 shows the schematic of the structure unit of the LSMMs. Adsorption capacity, $150.376 \mathrm{mg} \mathrm{g}^{-1}$ was reported for adsorption of malachite green (MG) dye. This synthesized material was mesoporous confirmed by using $\mathrm{N}_{2}$ adsorption/desorption. The mesoporous structure was affirmed from capillary action at around $\mathrm{P} / \mathrm{P}_{0}=0.45-1.0$ and diameter of $3.8 \mathrm{~nm}$. High BET surface area of $118 \mathrm{~m}^{2} \mathrm{~g}^{-1}$ for lignin sulfonate-g-poly (acrylic acid-r-acrylamide) was mentioned. The adsorption of the malachite green (MG) dye was confirmed through FTIR (Figure 16) and SEM. The structure of lignin sulfonate-g-poly (acrylic acid-r-acrylamide) (Figure 17b) was rough and porous in comparison to lignin sulfonate (Figure 17a). Hence adsorption efficiency was improved with the presence of pores in lignin sulfonate-g-poly (acrylic acid-r-acrylamide). The hydrogel of acylated hemicelluloses, acrylic acid and sodium lignosulfonate was prepared by using initiator ammonium persulfate and $\mathrm{N}, \mathrm{N}, \mathrm{N}^{\prime}, \mathrm{N}^{\prime}$-tetramethylethane-1,2-diamine with high adsorption capacity of for $2691 \mathrm{mg} \mathrm{g}^{-1}$ methylene blue dye [97]. The effect of sodium lignosulfonate on the morphology of prepared hydrogel was studied in detail. The honeycomb-like morphology was observed for all samples. The pore size of hydrogel was not affected by the sodium lignosulfonate concentration. In this work, sodium lignosulfonate dosage was found to exhibit a 
strong influence on the swelling ratio as well as the adsorption capacity. The adsorption kinetics was fitted with pseudo-second-order kinetics and isotherm well fitted by Langmuir isotherm. Even after the further cycle, the hydrogel was found to exhibit an approximately $80 \%$ adsorption efficiency and was proposed to be a promising material for dye wastewater treatment [97]. Luo et al. have also developed hydrogel of kraft lignin- $N$-isopropyl acrylamide and applied for the removal of methylene blue dye from aqueous solution [98]. Gassara et al. have also reported their studies on the usage of manganese peroxidase, lignin peroxidase and laccase with polyacrylamide hydrogel and pectin for the degradation of bisphenol A [99]. Bisphenol A degradation was low by using free enzyme while it was high with encapsulated enzymes on hydrogel. Figure 18 shows the possible pathways of degradation of bisphenol A. The enzyme activity was found to be increased in the presence of pectin.

\section{Conclusion \& Future Trends}

The number of published articles is increasing [53] continuously on synthesis and characterization of lignin based materials for different types of applications as indicated in Figure 19. The published articles are more on biopolymers such as starch and cellulose in comparison to lignin. This is due to the following reasons: (a) biopolymers such as cellulose and starch can be applied in diverse applications and (b) still there are several issues related to lignin valorization such as complexity, economical and technical aspects. Technologies for the production of lignin can be improved in order to increase the further interest in lignin based materials.

Nanomaterials have been utilized for various applications [103-105]. The mechanical strength as well as adsorption efficiency of lignin hydrogels can be improved by incorporating 
nanomaterials into their matrix [25,30,31,106-110]. To the best of our knowledge, up to date there is only one article on lignin based hydrogel using graphene oxide [88] as already discussed in this review. Hence different nanomaterials such as silicate nanoparticles, metal oxide nanoparticles, nanocellulose, graphene, carbon nanotubes and graphene oxide can be used with lignin hydrogels to develop new materials for the removal of various pollutants from water or wastewater [110-115].

\section{References}

[1] M. Khan, I.M. Lo, A holistic review of hydrogel applications in the adsorptive removal of aqueous pollutants: Recent progress, challenges, and perspectives, Water Res. 106 (2016) 259-271.

[2] E.M. Ahmed, Hydrogel: Preparation, characterization, and applications: A review, J. Adv. Res. 6 (2015) 105-121.

[3] T.L. Sun, T. Kurokawa, S. Kuroda, A.B. Ihsan, T. Akasaki, K. Sato, M.A. Haque, T. Nakajima, J.P. Gong, Physical hydrogels composed of polyampholytes demonstrate high toughness and viscoelasticity, Nat. Mater. 12 (2013) 932-937.

[4] J. Jagur-Grodzinski, Polymeric gels and hydrogels for biomedical and pharmaceutical applications, Polym. Adv. Technol. 21 (2010) 27-47.

[5] L.Z. Zhao, C.H. Zhou, J. Wang, D.S. Tong, W.H. Yu, H. Wang, Recent advances in clay mineral-containing nanocomposite hydrogels, Soft Matter. 11 (2015) 9229-9246.

[6] J. Kopeček, J. Yang, Hydrogels as smart biomaterials, Polym. Int. 56 (2007) 1078-1098.

[7] S. Khan, A. Ullah, K. Ullah, N. Rehman, Insight into hydrogels, Des. Monomers Polym. 19 (2016) 456-478. 
[8] J.W. Steed, Supramolecular gel chemistry: developments over the last decade, Chem. Commun. 47 (2011) 1379-1383.

[9] E.A. Appel, M.W. Tibbitt, M.J. Webber, B.A. Mattix, O. Veiseh, R. Langer, Selfassembled hydrogels utilizing polymer-nanoparticle interactions, Nat. Commun. 6 (2015). http://www.nature.com/ncomms/2015/150219/ncomms7295/full/ncomms7295.html?con=\& dom=prime\&src=syndication $($ accessed May 13, 2017).

[10] L. Liu, X. Tang, Y. Wang, S. Guo, Smart gelation of chitosan solution in the presence of NaHCO 3 for injectable drug delivery system, Int. J. Pharm. 414 (2011) 6-15.

[11] M.M. Pakulska, B.G. Ballios, M.S. Shoichet, Injectable hydrogels for central nervous system therapy, Biomed. Mater. 7 (2012) 024101.

[12] A. Parisi-Amon, W. Mulyasasmita, C. Chung, S.C. Heilshorn, Protein-Engineered Injectable Hydrogel to Improve Retention of Transplanted Adipose-Derived Stem Cells, Adv. Healthc. Mater. 2 (2013) 428-432.

[13] D.G. Barrett, D.E. Fullenkamp, L. He, N. Holten-Andersen, K.Y.C. Lee, P.B. Messersmith, pH-Based Regulation of Hydrogel Mechanical Properties Through Mussel-Inspired Chemistry and Processing, Adv. Funct. Mater. 23 (2013) 1111-1119.

[14] K. Adesanya, E. Vanderleyden, A. Embrechts, P. Glazer, E. Mendes, P. Dubruel, Properties of electrically responsive hydrogels as a potential dynamic tool for biomedical applications, J. Appl. Polym. Sci. 131 (2014). http://onlinelibrary.wiley.com/doi/10.1002/app.41195/full (accessed May 13, 2017).

[15] M.K. Thakur, V.K. Thakur, R.K. Gupta, A. Pappu, Synthesis and Applications of Biodegradable Soy Based Graft Copolymers: A Review, ACS Sustain. Chem. Eng. 4 (2016) 1-17. doi:10.1021/acssuschemeng.5b01327. 
[16] L.-W. Xia, R. Xie, X.-J. Ju, W. Wang, Q. Chen, L.-Y. Chu, Nano-structured smart hydrogels with rapid response and high elasticity, Nat. Commun. 4 (2013). http://www.nature.com/ncomms/2013/130731/ncomms3226/full/ncomms3226.html (accessed May 14, 2017).

[17] M.K. Shin, G.M. Spinks, S.R. Shin, S.I. Kim, S.J. Kim, Nanocomposite hydrogel with high toughness for bioactuators, Adv. Mater. 21 (2009) 1712-1715.

[18] S. ur Rehman, M. Siddiq, H. Al-Lohedan, N. Aktas, M. Sahiner, S. Demirci, N. Sahiner, Fast removal of high quantities of toxic arsenate via cationic p (APTMACl) microgels, J. Environ. Manage. 166 (2016) 217-226.

[19] M. Khan, I.M. Lo, Removal of ionizable aromatic pollutants from contaminated water using nano $\gamma$-Fe 2 O 3 based magnetic cationic hydrogel: Sorptive performance, magnetic separation and reusability, J. Hazard. Mater. 322 (2017) 195-204.

[20] Y. Li, G. Huang, X. Zhang, B. Li, Y. Chen, T. Lu, T.J. Lu, F. Xu, Magnetic Hydrogels and Their Potential Biomedical Applications, Adv. Funct. Mater. 23 (2013) 660-672. doi:10.1002/adfm.201201708.

[21] A. Musetti, K. Paderni, P. Fabbri, A. Pulvirenti, M. Al-Moghazy, P. Fava, Poly(vinyl alcohol)-Based Film Potentially Suitable for Antimicrobial Packaging Applications, J. Food Sci. 79 (2014) E577-E582. doi:10.1111/1750-3841.12375.

[22] G. Cirillo, F.P. Nicoletta, M. Curcio, U.G. Spizzirri, N. Picci, F. Iemma, Enzyme immobilization on smart polymers: Catalysis on demand, React. Funct. Polym. 83 (2014) 62-69. doi:10.1016/j.reactfunctpolym.2014.07.010. 
[23] N. Sahiner, F. Seven, The use of superporous p(AAc (acrylic acid)) cryogels as support for $\mathrm{Co}$ and $\mathrm{Ni}$ nanoparticle preparation and as reactor in $\mathrm{H} 2$ production from sodium borohydride hydrolysis, Energy. 71 (2014) 170-179. doi:10.1016/j.energy.2014.04.031.

[24] M. Takafuji, M.A. Alam, H. Goto, H. Ihara, Microspherical hydrogel particles based on silica nanoparticle-webbed polymer networks, J. Colloid Interface Sci. 455 (2015) 32-38. doi:10.1016/j.jcis.2015.05.034.

[25] A.K. Gaharwar, N.A. Peppas, A. Khademhosseini, Nanocomposite hydrogels for biomedical applications, Biotechnol. Bioeng. 111 (2014) 441-453. doi:10.1002/bit.25160.

[26] G. Jing, L. Wang, H. Yu, W.A. Amer, L. Zhang, Recent progress on study of hybrid hydrogels for water treatment, Colloids Surf. Physicochem. Eng. Asp. 416 (2013) 86-94. doi:10.1016/j.colsurfa.2012.09.043.

[27] R. Fang, W. He, H. Xue, W. Chen, Synthesis and characterization of a high-capacity cationic hydrogel adsorbent and its application in the removal of Acid Black 1 from aqueous solution, React. Funct. Polym. 102 (2016) 1-10.

[28] S.W. Kim, Y.H. Bae, T. Okano, Hydrogels: swelling, drug loading, and release, Pharm. Res. 9 (1992) 283-290.

[29] S. Amin, S. Rajabnezhad, K. Kohli, Hydrogels as potential drug delivery systems, Sci. Res. Essays. 4 (2009) 1175-1183.

[30] S. Thakur, S. Pandey, O.A. Arotiba, Development of a sodium alginate-based organic/inorganic superabsorbent composite hydrogel for adsorption of methylene blue, Carbohydr. Polym. 153 (2016) 34-46. doi:10.1016/j.carbpol.2016.06.104. 
[31] S. Thakur, O. Arotiba, Synthesis, characterization and adsorption studies of an acrylic acidgrafted sodium alginate-based $\mathrm{TiO} 2$ hydrogel nanocomposite, Adsorpt. Sci. Technol. (2017) 0263617417700636.

[32] R. Singhal, K. Gupta, A Review: Tailor-made Hydrogel Structures (Classifications and Synthesis Parameters), Polym.-Plast. Technol. Eng. 55 (2016) 54-70.

[33] N.A. Peppas, R.M. Ottenbrite, K. Park, T. Okano, Biomedical applications of hydrogels handbook, Springer Science \& Business Media, 2010. https://books.google.co.za/books?hl=en\&lr=\&id=PRvZdNXoOMC\&oi=fnd\&pg=PR1\&dq=Biomedical+Applications+of+Hydrogels+Handbook,+Springer :+New+York,\&ots=8SIzCq61i-\&sig=fX7GKM351wFp7JGSgkRqUxeBnh0 (accessed May 14, 2017).

[34] H. Zhang, F. Zhang, J. Wu, Physically crosslinked hydrogels from polysaccharides prepared by freeze-thaw technique, React. Funct. Polym. 73 (2013) 923-928.

[35] E. Moreno, J. Schwartz, E. Larrañeta, P.A. Nguewa, C. Sanmartín, M. Agüeros, J.M. Irache, S. Espuelas, Thermosensitive hydrogels of poly (methyl vinyl ether-co-maleic anhydride)-Pluronic ${ }^{\circledR}$ F127 copolymers for controlled protein release, Int. J. Pharm. 459 (2014) 1-9.

[36] A.A. Amini, L.S. Nair, Injectable hydrogels for bone and cartilage repair, Biomed. Mater. 7 (2012) 024105.

[37] E. Tous, B. Purcell, J.L. Ifkovits, J.A. Burdick, Injectable acellular hydrogels for cardiac repair, J Cardiovasc. Transl. Res. 4 (2011) 528-542. 
[38] S.J. Buwalda, K.W. Boere, P.J. Dijkstra, J. Feijen, T. Vermonden, W.E. Hennink, Hydrogels in a historical perspective: From simple networks to smart materials, J. Controlled Release. 190 (2014) 254-273.

[39] A. Chenite, C. Chaput, D. Wang, C. Combes, M.D. Buschmann, C.D. Hoemann, J.C. Leroux, B.L. Atkinson, F. Binette, A. Selmani, Novel injectable neutral solutions of chitosan form biodegradable gels in situ, Biomaterials. 21 (2000) 2155-2161.

[40] O. Wichterle, D. Lim, Hydrophilic gels for biological use, Nature. 185 (1960) 117-118.

[41] Y. Li, C. Liu, Y. Tan, K. Xu, C. Lu, P. Wang, In situ hydrogel constructed by starch-based nanoparticles via a Schiff base reaction, Carbohydr. Polym. 110 (2014) 87-94.

[42] R. Singh, D. Singh, Radiation synthesis of PVP/alginate hydrogel containing nanosilver as wound dressing, J. Mater. Sci. Mater. Med. 23 (2012) 2649-2658.

[43] K. Ren, C. He, Y. Cheng, G. Li, X. Chen, Injectable enzymatically crosslinked hydrogels based on a poly (1-glutamic acid) graft copolymer, Polym. Chem. 5 (2014) 5069-5076.

[44] J.W. Bae, J.H. Choi, Y. Lee, K.D. Park, Horseradish peroxidase-catalysed in situ-forming hydrogels for tissue-engineering applications, J. Tissue Eng. Regen. Med. 9 (2015) 12251232.

[45] R. Fang, W. He, H. Xue, W. Chen, Synthesis and characterization of a high-capacity cationic hydrogel adsorbent and its application in the removal of Acid Black 1 from aqueous solution, React. Funct. Polym. 102 (2016) 1-10.

[46] V.K. Thakur, M.K. Thakur, Recent trends in hydrogels based on psyllium polysaccharide: a review, J. Clean. Prod. 82 (2014) 1-15.

[47] V.K. Thakur, S.I. Voicu, Recent advances in cellulose and chitosan based membranes for water purification: a concise review, Carbohydr. Polym. 146 (2016) 148-165. 
[48] V.K. Thakur, M.K. Thakur, Recent advances in green hydrogels from lignin: a review, Int. J. Biol. Macromol. 72 (2015) 834-847.

[49] V.K. Thakur, D. Vennerberg, S. A. Madbouly, M. R. Kessler, Bio-inspired green surface functionalization of PMMA for multifunctional capacitors, RSC Adv. 4 (2014) 6677-6684. doi: 10.1039/C3RA46592F.

[50] A.S. Singha, V.K. Thakur, Fabrication and study of lignocellulosic hibiscus sabdariffa fiber reinforced polymer composites, BioResources. 3 (2008) 1173-1186.

[51] V.K. Thakur, M.K. Thakur, P. Raghavan, M.R. Kessler, Progress in Green Polymer Composites from Lignin for Multifunctional Applications: A Review, ACS Sustain. Chem. Eng. 2 (2014) 1072-1092. doi:10.1021/sc500087z.

[52] F.N.U. Asina, I. Brzonova, E. Kozliak, A. Kubátová, Y. Ji, Microbial treatment of industrial lignin: Successes, problems and challenges, Renew. Sustain. Energy Rev. (2017). http://www.sciencedirect.com/science/article/pii/S1364032117304343 (accessed May 14, 2017).

[53] D. Kun, B. Pukánszky, Polymer/Lignin blends: Interactions, properties, applications, Eur. Polym. J. (2017). http://www.sciencedirect.com/science/article/pii/S0014305716317529 (accessed May 14, 2017).

[54] C. Rutten, A. Ramírez, J. Posada Duque, Hydrotreating and hydrothermal treatment of alkaline lignin as technological valorization options for future biorefinery concepts: a review, J. Chem. Technol. Biotechnol. (2016). http://onlinelibrary.wiley.com/doi/10.1002/jctb.5103/full (accessed May 14, 2017).

[55] J. Dai, A.F. Patti, K. Saito, Recent developments in chemical degradation of lignin: catalytic oxidation and ionic liquids, Tetrahedron Lett. 57 (2016) 4945-4951. 
[56] E.P. Feofilova, I.S. Mysyakina, Lignin: Chemical structure, biodegradation, and practical application (a review), Appl. Biochem. Microbiol. 52 (2016) 573-581.

[57] A. Payen, Mémoire sur la composition du tissu propre des plantes et du ligneux, Comptes Rendus. 7 (1838) 1052-1056.

[58] V.K. Thakur, A.S. Singha, Natural fibres-based polymers: Part I-Mechanical analysis of Pine needles reinforced biocomposites, Bull. Mater. Sci. 33 (2010) 257-264. doi:10.1007/s12034-010-0040-x.

[59] A.S. Singha, V.K. Thakur, Fabrication and characterization of S. cilliare fibre reinforced polymer composites, Bull. Mater. Sci. 32 (2009) 49-58. doi:10.1007/s12034-009-0008-x.

[60] V.K. Thakur, A.S. Singha, M.K. Thakur, Green composites from natural fibers: Mechanical and chemical aging properties, Int. J. Polym. Anal. Charact. 17 (2012) 401-407.

[61] A.S. Singha, V.K. Thakur, STUDY OF MECHANICAL PROPERTIES OF UREAFORMALDEHYDE THERMOSETS REINFORCED BY PINE NEEDLE POWDER, BioResources. 4 (2009) 292-308. doi:10.15376/biores.4.1.292-308.

[62] J.-P. Lange, Lignocellulose conversion: an introduction to chemistry, process and economics, Biofuels Bioprod. Biorefining. 1 (2007) 39-48.

[63] M. FitzPatrick, P. Champagne, M.F. Cunningham, R.A. Whitney, A biorefinery processing perspective: treatment of lignocellulosic materials for the production of value-added products, Bioresour. Technol. 101 (2010) 8915-8922.

[64] S. Fernando, S. Adhikari, C. Chandrapal, N. Murali, Biorefineries: current status, challenges, and future direction, Energy Fuels. 20 (2006) 1727-1737. 
[65] A.S. Singha, V.K. Thakur, Mechanical, Thermal and Morphological Properties of Grewia Optiva Fiber/Polymer Matrix Composites, Polym.-Plast. Technol. Eng. 48 (2009) 201-208. doi:10.1080/03602550802634550.

[66] A.S. Singha, V.K. Thakur, Synthesis and Characterization of Grewia Optiva Fiberreinforced PF-based Composites, Int. J. Polym. Mater. Polym. Biomater. 57 (2008) 10591074. doi:10.1080/00914030802257800.

[67] V.K. Thakur, A.S. Singha, M.K. Thakur, Surface modification of natural polymers to impart low water absorbency, Int. J. Polym. Anal. Charact. 17 (2012) 133-143.

[68] V.K. Thakur, A.S. Singha, M.K. Thakur, In-air graft copolymerization of ethyl acrylate onto natural cellulosic polymers, Int. J. Polym. Anal. Charact. 17 (2012) 48-60.

[69] M.E. Brown, M.C. Chang, Exploring bacterial lignin degradation, Curr. Opin. Chem. Biol. 19 (2014) $1-7$.

[70] V.K. Thakur, M.K. Thakur, R.K. Gupta, Graft Copolymers from Natural Polymers Using Free Radical Polymerization, Int. J. Polym. Anal. Charact. 18 (2013) 495-503. doi:10.1080/1023666X.2013.814241.

[71] V.K. Thakur, A.S. Singha, M.K. Thakur, Ecofriendly Biocomposites from Natural fibers: Mechanical and Weathering study, Int. J. Polym. Anal. Charact. 18 (2013) 64-72. doi:10.1080/1023666X.2013.747246.

[72] L. Jouanin, C. Lapierre, Lignins: biosynthesis, biodegradation and bioengineering, Academic Press, 2012.

https://books.google.co.za/books?hl=en\&lr=\&id=Wa7i9ZzjUVMC\&oi=fnd\&pg=PP2\&dq=Ligni ns:+biosynthesis,+biodegradation+and+bioengineering.\&ots=WE6TGu54tG\&sig=q9WCG v-TC2GFRTCRpXzIHtojwTA (accessed May 14, 2017). 
[73] P. Phitsuwan, K. Sakka, K. Ratanakhanokchai, Improvement of lignocellulosic biomass in planta: a review of feedstocks, biomass recalcitrance, and strategic manipulation of ideal plants designed for ethanol production and processability, Biomass Bioenergy. 58 (2013) 390-405.

[74] M. Li, Y. Pu, A.J. Ragauskas, Current understanding of the correlation of lignin structure

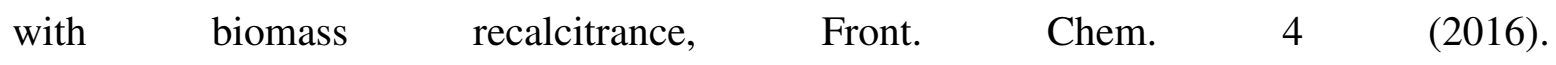
https://www.ncbi.nlm.nih.gov/pmc/articles/PMC5114238/ (accessed May 14, 2017).

[75] R. Vanholme, B. Demedts, K. Morreel, J. Ralph, W. Boerjan, Lignin biosynthesis and structure, Plant Physiol. 153 (2010) 895-905.

[76] W. Boerjan, J. Ralph, M. Baucher, Lignin biosynthesis, Annu. Rev. Plant Biol. 54 (2003) $519-546$.

[77] M. Li, Y. Pu, C.G. Yoo, A.J. Ragauskas, The occurrence of tricin and its derivatives in plants, Green Chem. 18 (2016) 1439-1454.

[78] C.G. Yoo, Y. Pu, M. Li, A.J. Ragauskas, Elucidating Structural Characteristics of Biomass using Solution-State 2 D NMR with a Mixture of Deuterated Dimethylsulfoxide and Hexamethylphosphoramide, ChemSusChem. 9 (2016) 1090-1095.

[79] S.M. Notley, M. Norgren, others, Lignin: Functional biomaterial with potential in surface chemistry and nanoscience, Nanosci. Technol. Renew. Biomater. (2009) 173-206.

[80] K. Freudenberg, A.C. Neish, others, Constitution and biosynthesis of lignin., Const. Biosynth. Lignin. (1968). https://www.cabdirect.org/cabdirect/abstract/19680607153 (accessed May 14, 2017).

[81] K. Freudenberg, Lignin: its constitution and formation from p-hydroxycinnamyl alcohols, Science. 148 (1965) 595-600. 
[82] E. Adler, Lignin chemistry_past, present and future, Wood Sci. Technol. 11 (1977) 169218.

[83] G. Brunow, I. Kilpeläinen, J. Sipilä, K. Syrjänen, P. Karhunen, H. Setälä, P. Rummakko, Oxidative coupling of phenols and the biosynthesis of lignin, in: ACS Publications, 1998. http://pubs.acs.org/doi/abs/10.1021/bk-1998-0697.ch010 (accessed May 14, 2017).

[84] G. Gellerstedt, Lignin complexity: fundamental and applied issues, 2007. http://www.cnrs.fr/inc/recherche/programmes/docs/rdr1_26_11_07/gellerstedt.pdf (accessed May 14, 2017).

[85] H. Nimz, Beech lignin-proposal of a constitutional scheme, Angew. Chem. Int. Ed. Engl. 13 (1974) 313-321.

[86] M. Lawoko, G. Henriksson, G. Gellerstedt, Structural differences between the lignincarbohydrate complexes present in wood and in chemical pulps, Biomacromolecules. 6 (2005) 3467-3473.

[87] E.T. Engelund, L.G. Thygesen, S. Svensson, C.A.S. Hill, A critical discussion of the physics of wood-water interactions, Wood Sci. Technol. 47 (2013) 141-161. doi:10.1007/s00226-012-0514-7.

[88] F. Li, X. Wang, T. Yuan, R. Sun, A lignosulfonate-modified graphene hydrogel with ultrahigh adsorption capacity for $\mathrm{Pb}$ (ii) removal, J. Mater. Chem. A. 4 (2016) $11888-$ 11896.

[89] Y. Sun, Y. Ma, G. Fang, S. Li, Y. Fu, Synthesis of Acid Hydrolysis Lignin-g-Poly-(Acrylic Acid) Hydrogel Superabsorbent Composites and Adsorption of Lead Ions, BioResources. 11 (2016) 5731-5742. 
[90] Y. WANG, Y. XIONG, F.-L. SUN, Y.-Q. YANG, X.-D. ZHANG, Ultrasonic-Assisted Synthesis of a Superabsorbent Composite Hydrogel for the Responsive and Removal Properties of Pb (II), Acta Phys Chim Sin. 32 (2016) 2563-2573.

[91] H.W. Kwak, M. Shin, H. Yun, K.H. Lee, Preparation of Silk Sericin/Lignin Blend Beads for the Removal of Hexavalent Chromium Ions, Int. J. Mol. Sci. 17 (2016) 1466.

[92] D. Dax, M.S. Chávez, C. Xu, S. Willför, R.T. Mendonça, J. Sánchez, Cationic hemicellulose-based hydrogels for arsenic and chromium removal from aqueous solutions, Carbohydr. Polym. 111 (2014) 797-805.

[93] Q. Yao, J. Xie, J. Liu, H. Kang, Y. Liu, Adsorption of lead ions using a modified lignin hydrogel, J. Polym. Res. 21 (2014) 465.

[94] M.A. Sabino, others, Effect of the presence of lignin or peat in IPN hydrogels on the sorption of heavy metals, Polym. Bull. 65 (2010) 495-508.

[95] C. Yu, F. Wang, C. Zhang, S. Fu, L.A. Lucia, The synthesis and absorption dynamics of a lignin-based hydrogel for remediation of cationic dye-contaminated effluent, React. Funct. Polym. 106 (2016) 137-142.

[96] Y. Tang, Y. Zeng, T. Hu, Q. Zhou, Y. Peng, Preparation of lignin sulfonate-based mesoporous materials for adsorbing malachite green from aqueous solution, J. Environ. Chem. Eng. 4 (2016) 2900-2910.

[97] X. Song, F. Chen, S. Liu, A Lignin-containing Hemicellulose-based Hydrogel and its Adsorption Behavior, BioResources. 11 (2016) 6378-6392.

[98] H. Luo, S. Ren, Y. Ma, G. Fang, G. Jiang, Preparation and properties of kraft lignin-Nisopropyl acrylamide hydrogel, BioResources. 10 (2015) 3507-3519. 
[99] F. Gassara, S.K. Brar, M. Verma, R.D. Tyagi, Bisphenol A degradation in water by ligninolytic enzymes, Chemosphere. 92 (2013) 1356-1360.

[100] X. Teng, H. Xu, W. Song, J. Shi, J. Xin, W.C. Hiscox, J. Zhang, Preparation and Properties of Hydrogels Based on PEGylated Lignosulfonate Amine, ACS Omega. 2 (2017) $251-259$.

[101] E. Lian, R. Shi, Y. Deng, H. Zhu, Y. Ma, Adsorption of low cross-linking density hydrogel OMMT/acid hydrolysis lignin grafted polyacrylic acid for Cd (II), in: AIP Conf. Proc., AIP Publishing, 2017: p. 020001. http://aip.scitation.org/doi/abs/10.1063/1.4977249.

[102] Y. Ma, Y. Sun, Y. Fu, G. Fang, X. Yan, Z. Guo, Swelling behaviors of porous lignin based poly (acrylic acid), Chemosphere. 163 (2016) 610-619.

[103] M. Mehrali, A. Thakur, C.P. Pennisi, S. Talebian, A. Arpanaei, M. Nikkhah, A. Dolatshahi-Pirouz, Nanoreinforced Hydrogels for Tissue Engineering: Biomaterials that are Compatible with Load-Bearing and Electroactive Tissues, Adv. Mater. (2016). http://onlinelibrary.wiley.com/doi/10.1002/adma.201603612/full (accessed May 14, 2017).

[104] P. Khullar, V. Singh, A. Mahal, P.N. Dave, S. Thakur, G. Kaur, J. Singh, S. Singh Kamboj, M. Singh Bakshi, Bovine serum albumin bioconjugated gold nanoparticles: synthesis, hemolysis, and cytotoxicity toward cancer cell lines, J. Phys. Chem. C. 116 (2012) 8834-8843.

[105] H. Kaur, T.S. Banipal, S. Thakur, M.S. Bakshi, G. Kaur, N. Singh, Novel biodegradable films with extraordinary tensile strength and flexibility provided by nanoparticles, ACS Sustain. Chem. Eng. 1 (2012) 127-136. 
[106] A. Memic, H.A. Alhadrami, M.A. Hussain, M. Aldhahri, F. Al Nowaiser, F. Al-Hazmi, R. Oklu, A. Khademhosseini, Hydrogels 2.0: improved properties with nanomaterial composites for biomedical applications, Biomed. Mater. 11 (2015) 014104.

[107] Y. Zuo, X. Liu, D. Wei, J. Sun, W. Xiao, H. Zhao, L. Guo, Q. Wei, H. Fan, X. Zhang, Photo-cross-linkable methacrylated gelatin and hydroxyapatite hybrid hydrogel for modularly engineering biomimetic osteon, ACS Appl. Mater. Interfaces. 7 (2015) 1038610394.

[108] S.R. Shin, C. Shin, A. Memic, S. Shadmehr, M. Miscuglio, H.Y. Jung, S.M. Jung, H. Bae, A. Khademhosseini, X.S. Tang, others, Aligned Carbon Nanotube-Based Flexible Gel Substrates for Engineering Biohybrid Tissue Actuators, Adv. Funct. Mater. 25 (2015) 4486-4495.

[109] N. Annabi, S.R. Shin, A. Tamayol, M. Miscuglio, M.A. Bakooshli, A. Assmann, P. Mostafalu, J.-Y. Sun, S. Mithieux, L. Cheung, others, Highly Elastic and Conductive Human-Based Protein Hybrid Hydrogels, Adv. Mater. 28 (2016) 40-49.

[110] S.R. Shin, H. Bae, J.M. Cha, J.Y. Mun, Y.-C. Chen, H. Tekin, H. Shin, S. Farshchi, M.R. Dokmeci, S. Tang, others, Carbon nanotube reinforced hybrid microgels as scaffold materials for cell encapsulation, ACS Nano. 6 (2011) 362-372.

[111] D. Trache, M. Hazwan Hussin, M.K. Mohamad Haafiz, V. K. Thakur, Recent progress in cellulose nanocrystals: sources and production, Nanoscale. 9 (2017) 1763-1786. doi: 10.1039/C6NR09494E.

[112] V.K. Thakur, Y. Li, H. Wu, M.R. Kessler, Synthesis, characterization, and functionalization of zirconium tungstate ( $\mathrm{ZrW} 2 \mathrm{O} 8$ ) nano-rods for advanced polymer nanocomposites, Polym. Adv. Technol. (2017) n/a-n/a. doi:10.1002/pat.4014. 
[113] V.K. Thakur, A.S. Singha, M.K. Thakur, Biopolymers Based Green Composites: Mechanical, Thermal and Physico-chemical Characterization, J. Polym. Environ. 20 (2012) 412-421. doi: 10.1007/s10924-011-0389-y.

[114] S. Thakur, P.P. Govender, M.A. Mamo, S. Tamulevicius, V.K. Thakur, Recent progress in gelatin hydrogel nanocomposites for water purification and beyond, Vacuum. (2017). doi:10.1016/j.vacuum.2017.05.032.

[115] M.C. Corobea, O. Muhulet, F. Miculescu, I.V. Antoniac, Z. Vuluga, D. Florea, D.M. Vuluga, M. Butnaru, D. Ivanov, S.I. Voicu, others, Novel nanocomposite membranes from cellulose acetate and clay-silica nanowires, Polym. Adv. Technol. 27 (2016) 1586-1595. 
(a)

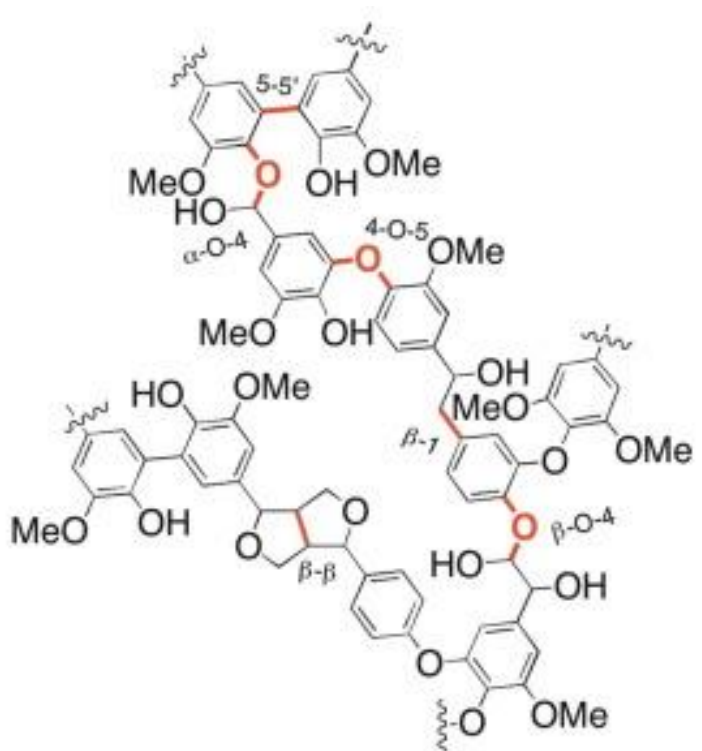

(b)
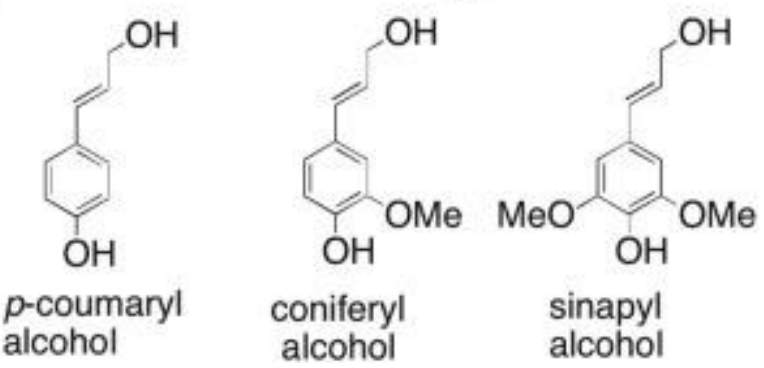

Figure 1. (a) Proposed lignin structure with several linkages; (b) three primary alcohol structures in lignin [55]. Reprinted with permission. [55] Copyright 2016 Elsevier. 


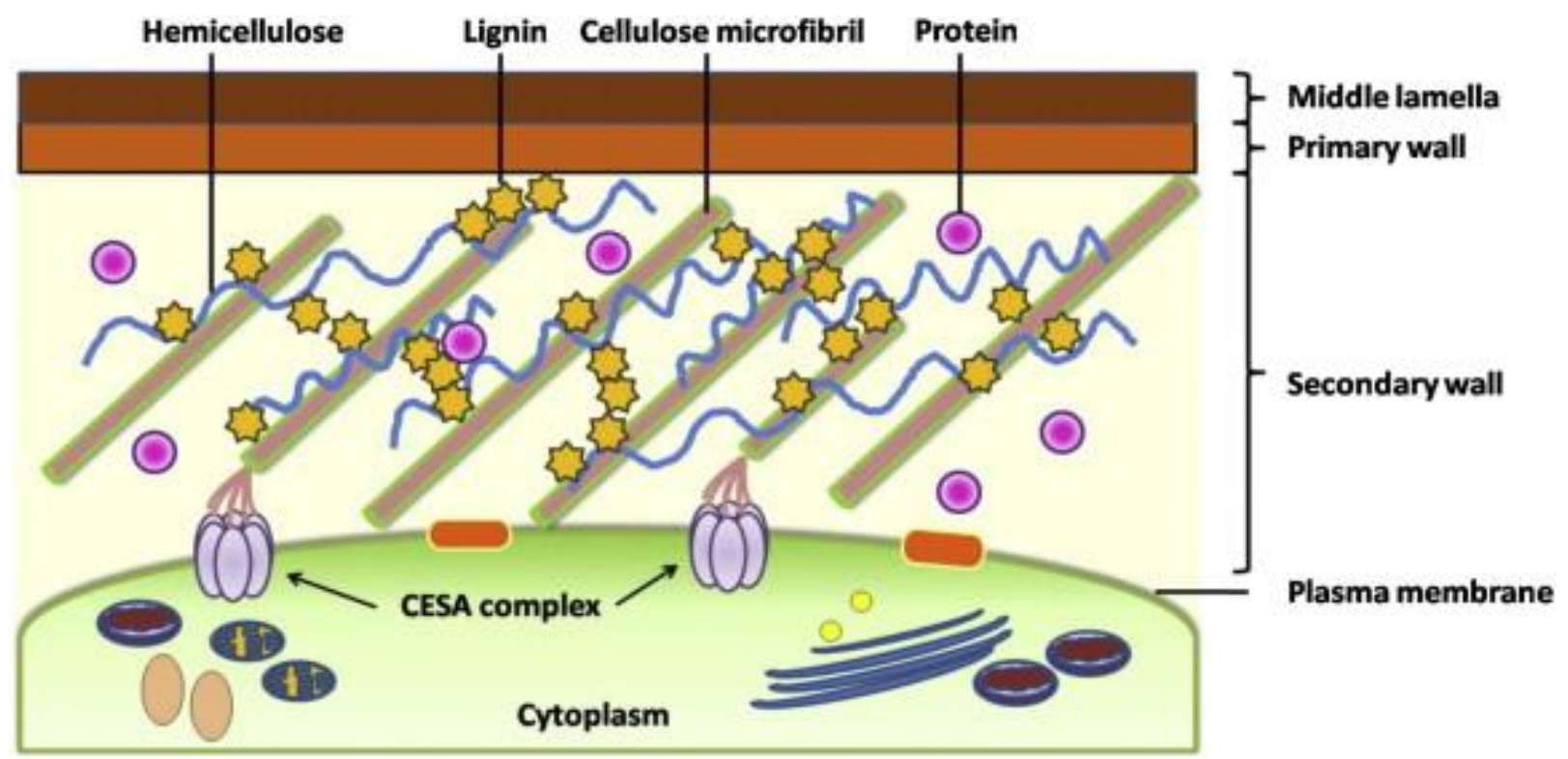

Figure 2. (a) Simplified diagram showing complex structures of plant cell walls [73]. Reprinted with permission. [73] Copyright 2013 Elsevier.

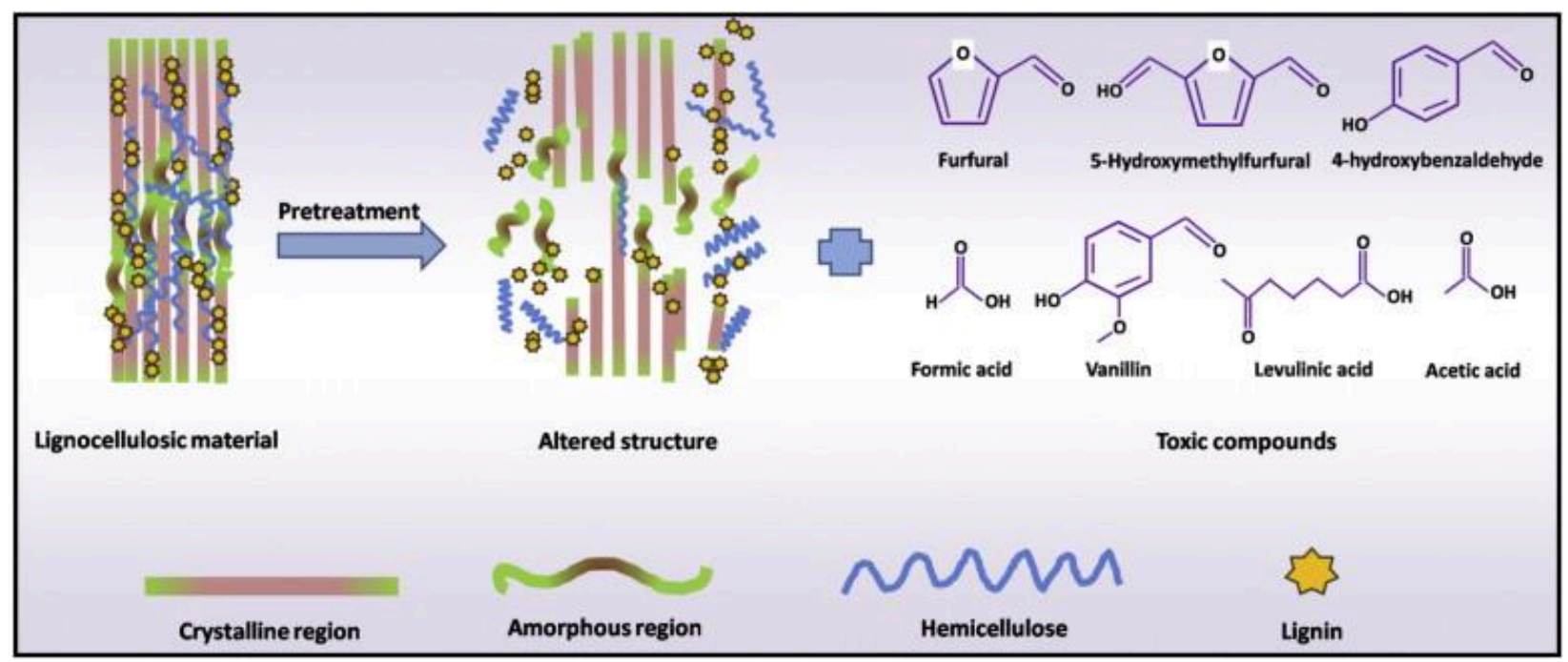


Figure 2. (b) Schematic representation of pre-treatment and possible lignocellulose-derived inhibitors (or toxic compounds) generated from pre-treatment [73]. Reprinted with permission. [73] Copyright 2013 Elsevier.
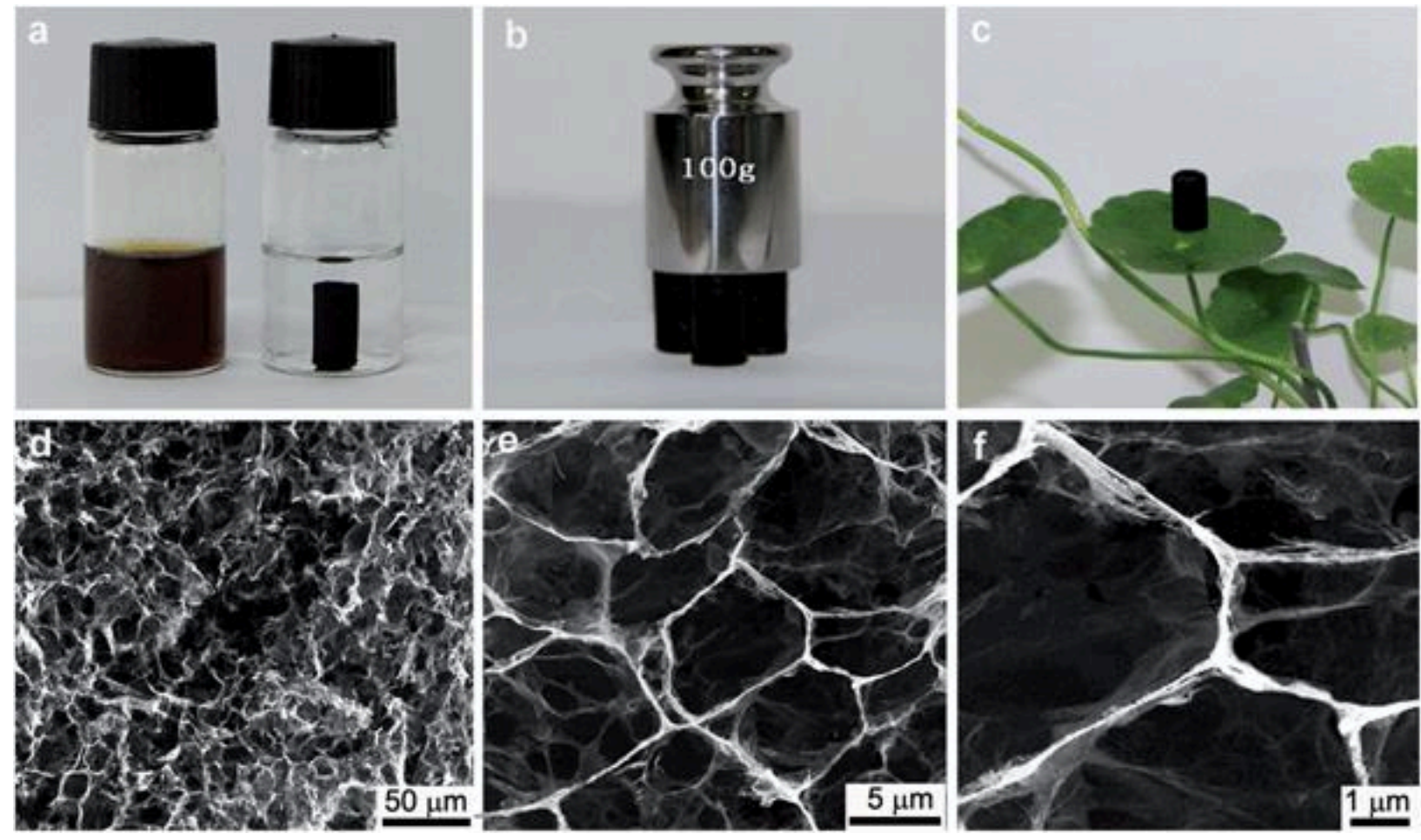

Figure 3. (a) Photographs of aqueous dispersion of lignosulfonate and graphene oxide before and after hydrothermal treatment, (b and c) photographs of strong and light lignosulfonate based graphene hydrogel, (d-f) SEM images for lignosulfonate based graphene hydrogel at various magnifications [88]. Reprinted with permission. [88] Copyright 2016 Royal Society of Chemistry. 

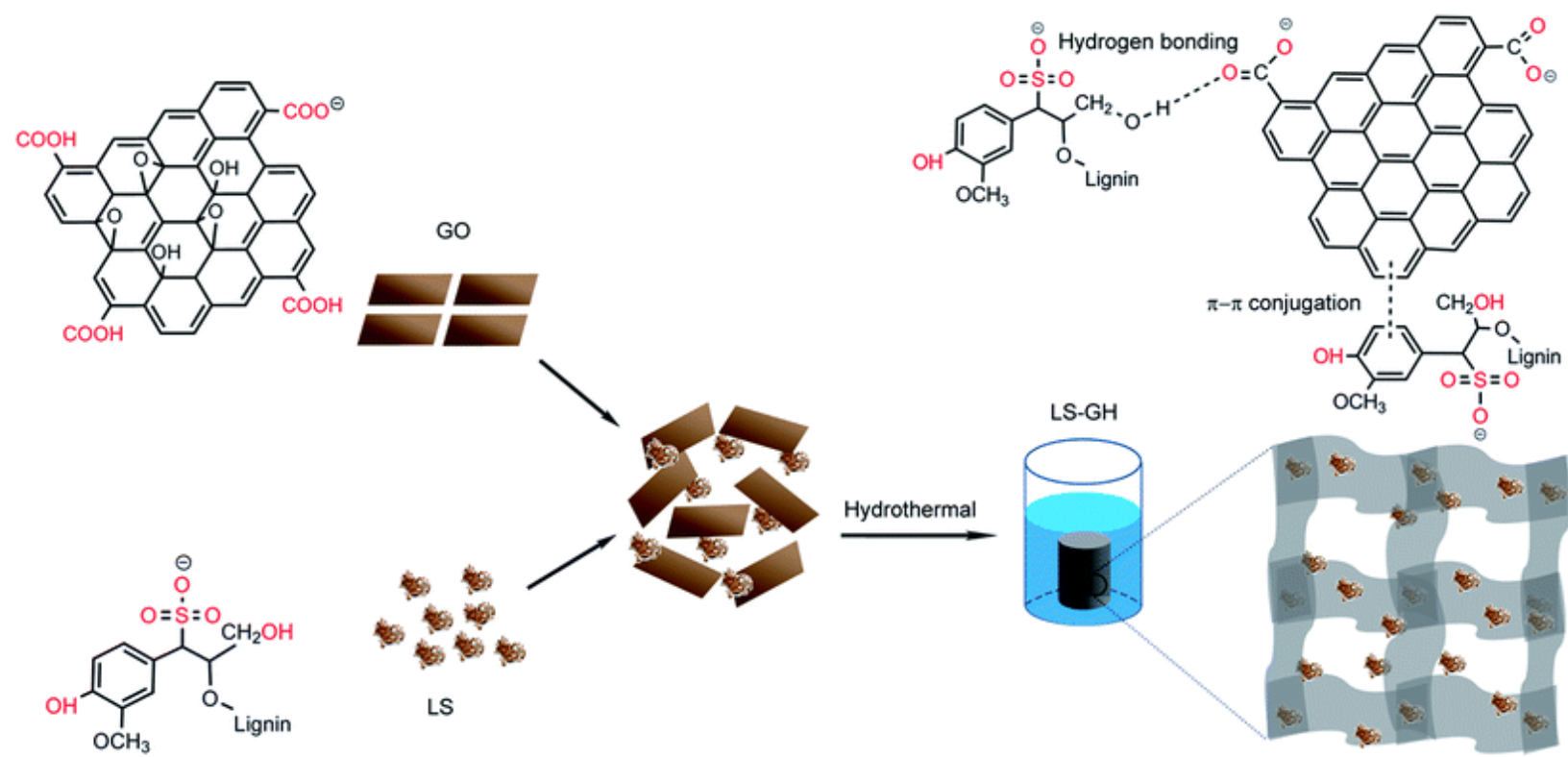

Figure 4. Schematic presentation for the formation of lignosulfonate based graphene hydrogel, hydrogen bonding and pi-pi interactions between reduced graphene oxide and lignosulfonate [88]. Reprinted with permission. [88] Copyright 2016 Royal Society of Chemistry. 
a

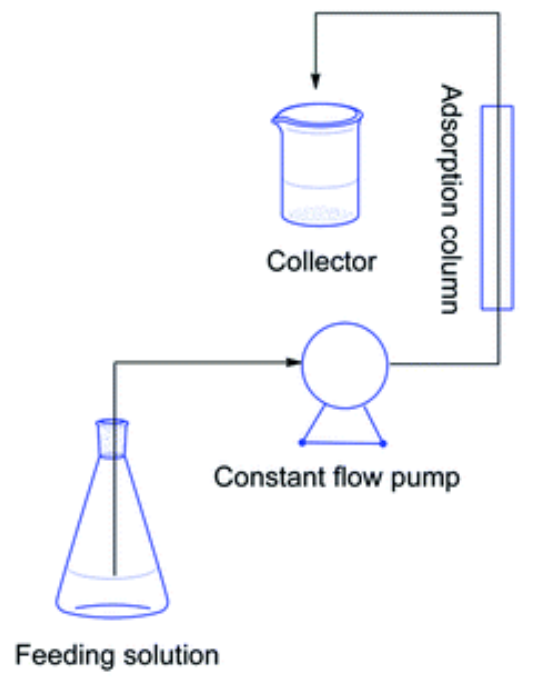

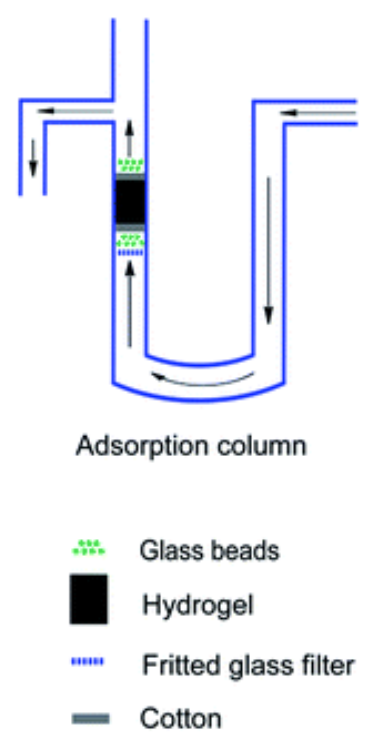

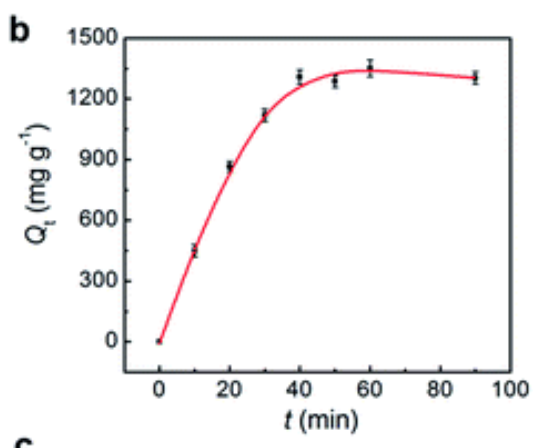

C

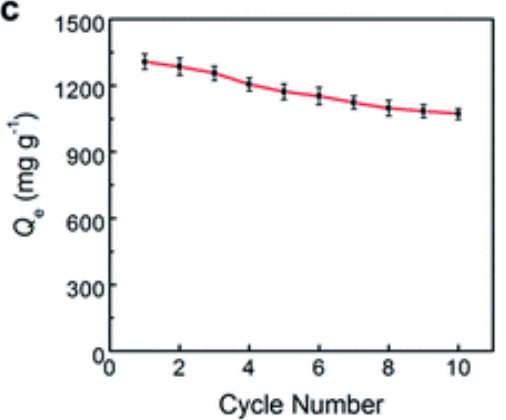

Figure 5. (a) Column-packed device schematic representation, (b) Adsorption capacities of lignosulfonate based graphene hydrogel with time for $\mathrm{Pb}^{2+}$ removal, (c) reusable and regeneration study of lignosulfonate based graphene hydrogel for $\mathrm{Pb}^{2+}$ removal [88]. Reprinted with permission. [88] Copyright 2016 Royal Society of Chemistry. 

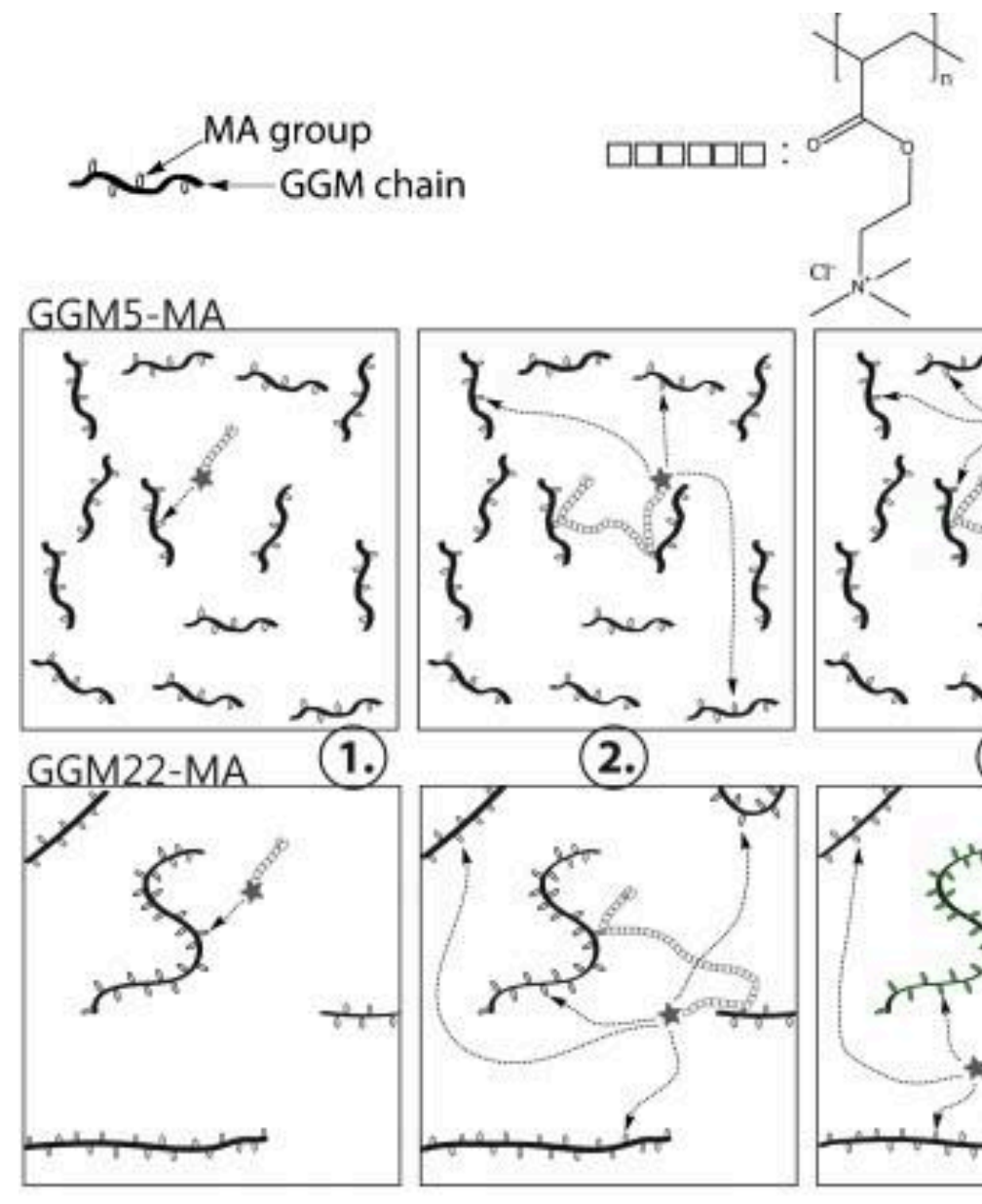

: $\begin{gathered}\text { active polymer chain end } \\ \text { (free radical) }\end{gathered}$

c.
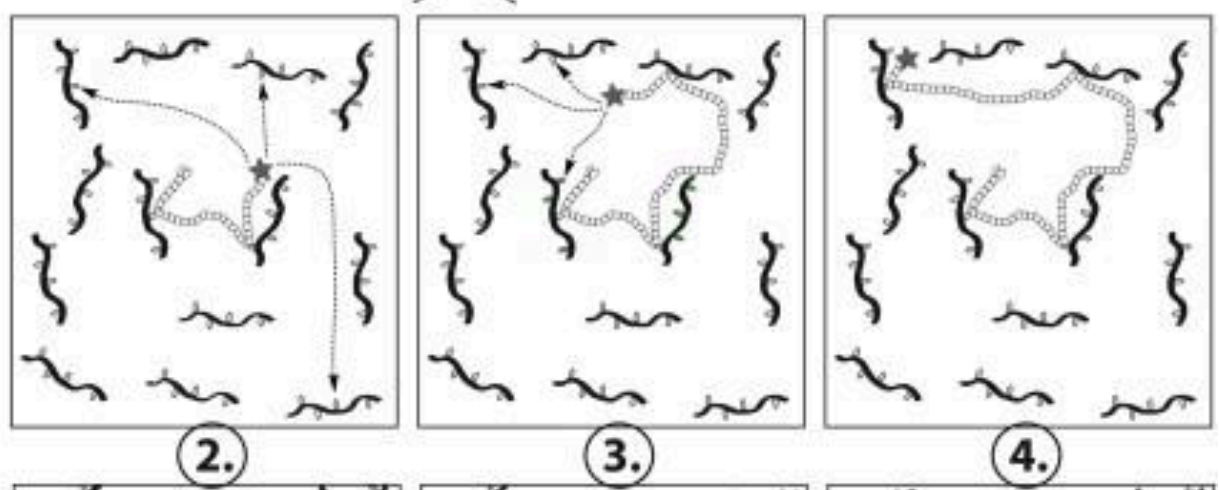

(2.)
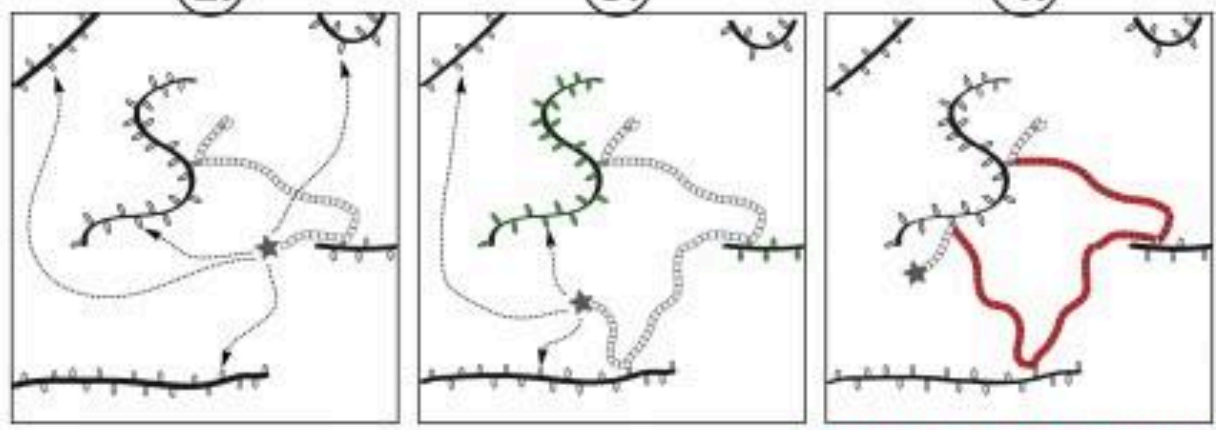

crosslinked network

Figure 6. Schematic representation of GGM-MA crosslinker with different molar mass. (1) and

(2) reaction of three GGM22-MA chains with active polymer chain, (3) more probability of interlinking of GGM22-MA chains in comparison to GGM5-MA due to the large quantity of MA groups (highlighted in green), (4) formation of crosslinked network of GGM22-MA [92]. GGM: O-acetyl galactoglucomannan macromonomers, MA: methacrylate groups, GGM5-MA $\left(\mathrm{M}_{\mathrm{n}}=\right.$ 
4.7 kDa), GGM22-MA ( $\left.\mathrm{M}_{\mathrm{n}}=21.5 \mathrm{kDa}\right)$ [92]. Reprinted with permission. [92] Copyright 2014 Elsevier.
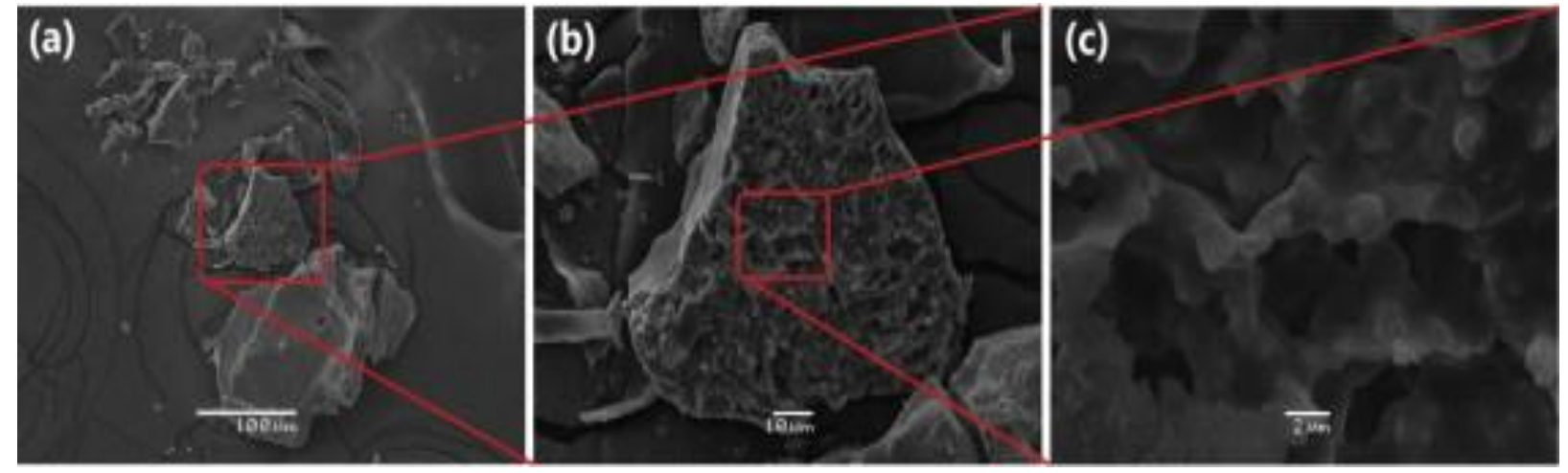

Figure 7. SEM images swelled GGM-based hydrogel at different magnification [92]. Reprinted with permission. [92] Copyright 2014 Elsevier. 


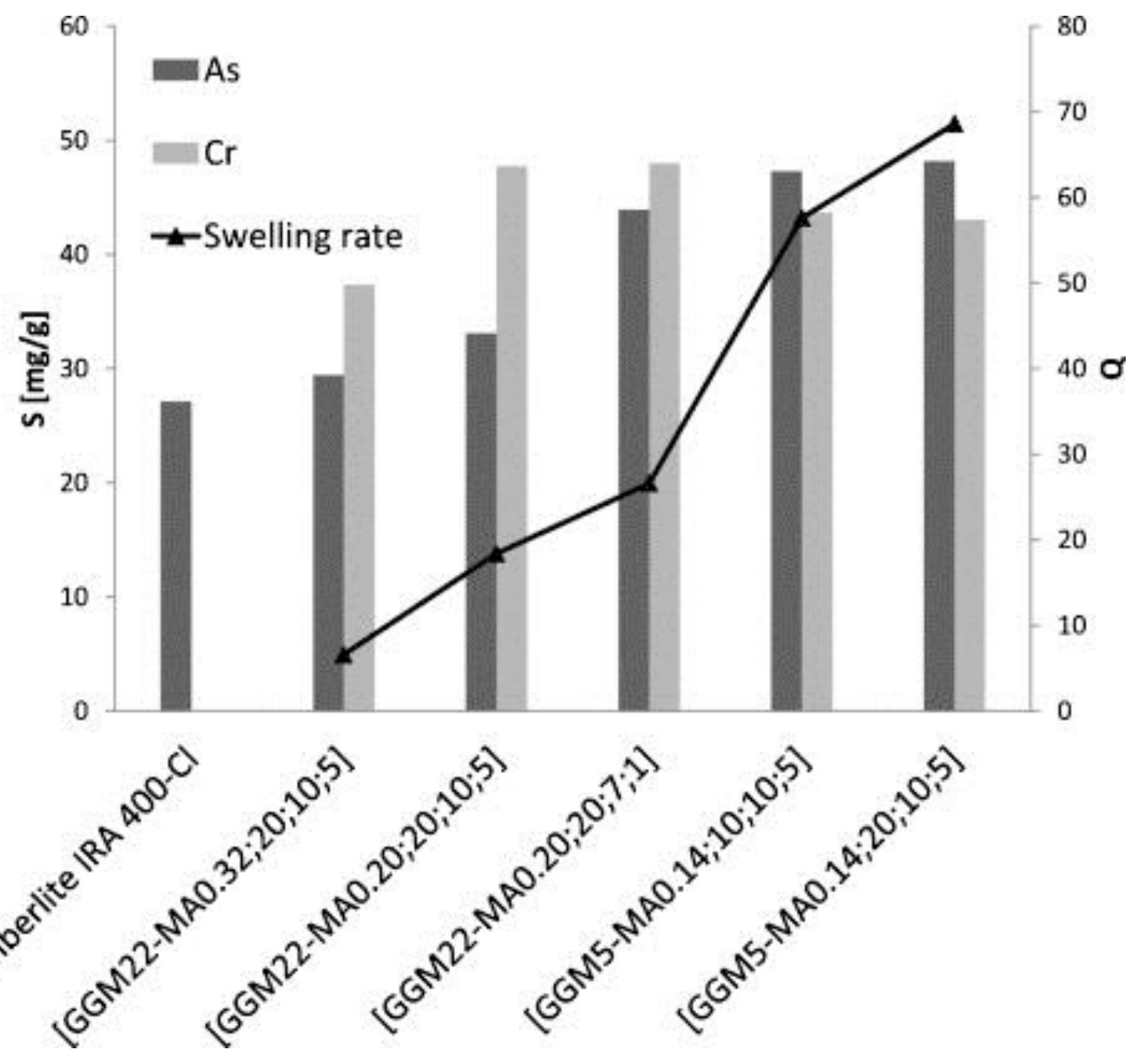

Figure 8. Sorption of As (V) and $\mathrm{Cr}(\mathrm{VI})$ for different hydrogels and Amberlite IRA 400-Cl as a commercial product [92]. Reprinted with permission. [92] Copyright 2014 Elsevier. 


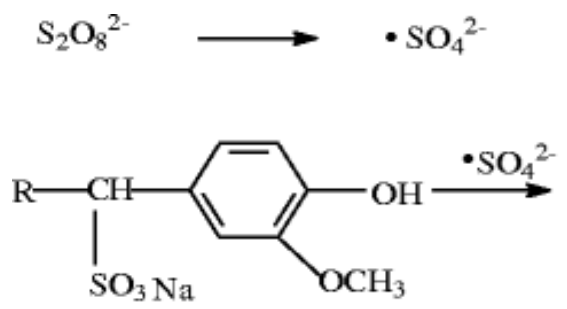

$\mathrm{A}(\mathrm{LS})$

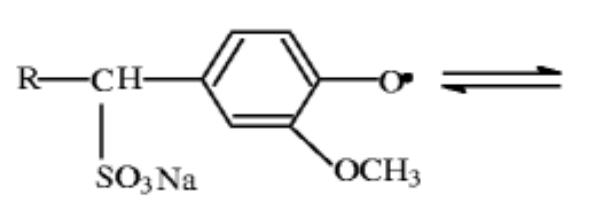

$\mathrm{B}(\mathrm{LS})$

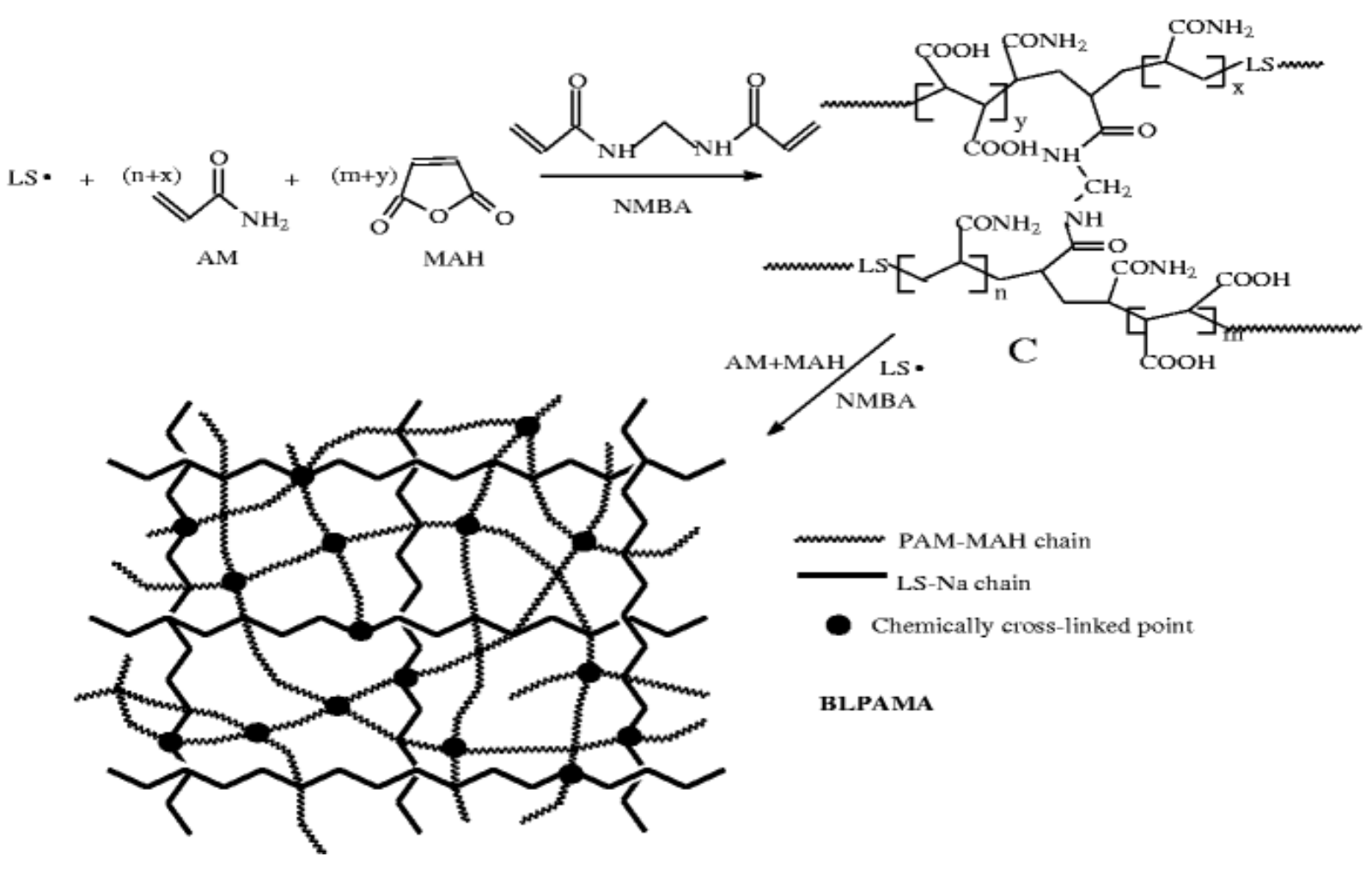

Figure 9. Proposed mechanism for the preparation of BLPAMA hydrogel [93]. Reprinted with permission. [93] Copyright 2014 Springer. 

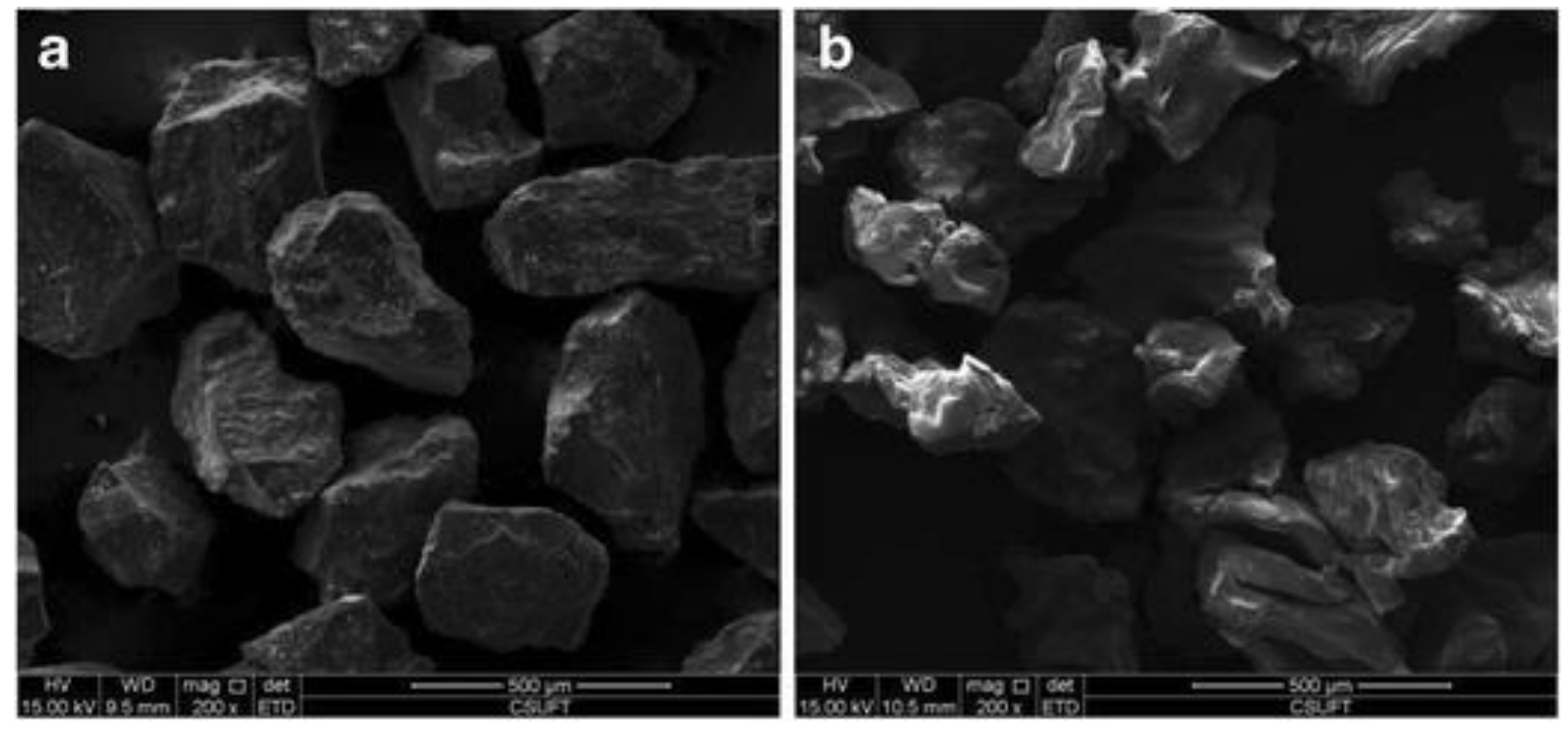

Figure 10. SEM micrographs of BLPAMA before (a) and after (b) $\mathrm{Pb}^{2+}$ adsorption (magnification: ×200) [93]. Reprinted with permission. [93] Copyright 2014 Springer. 


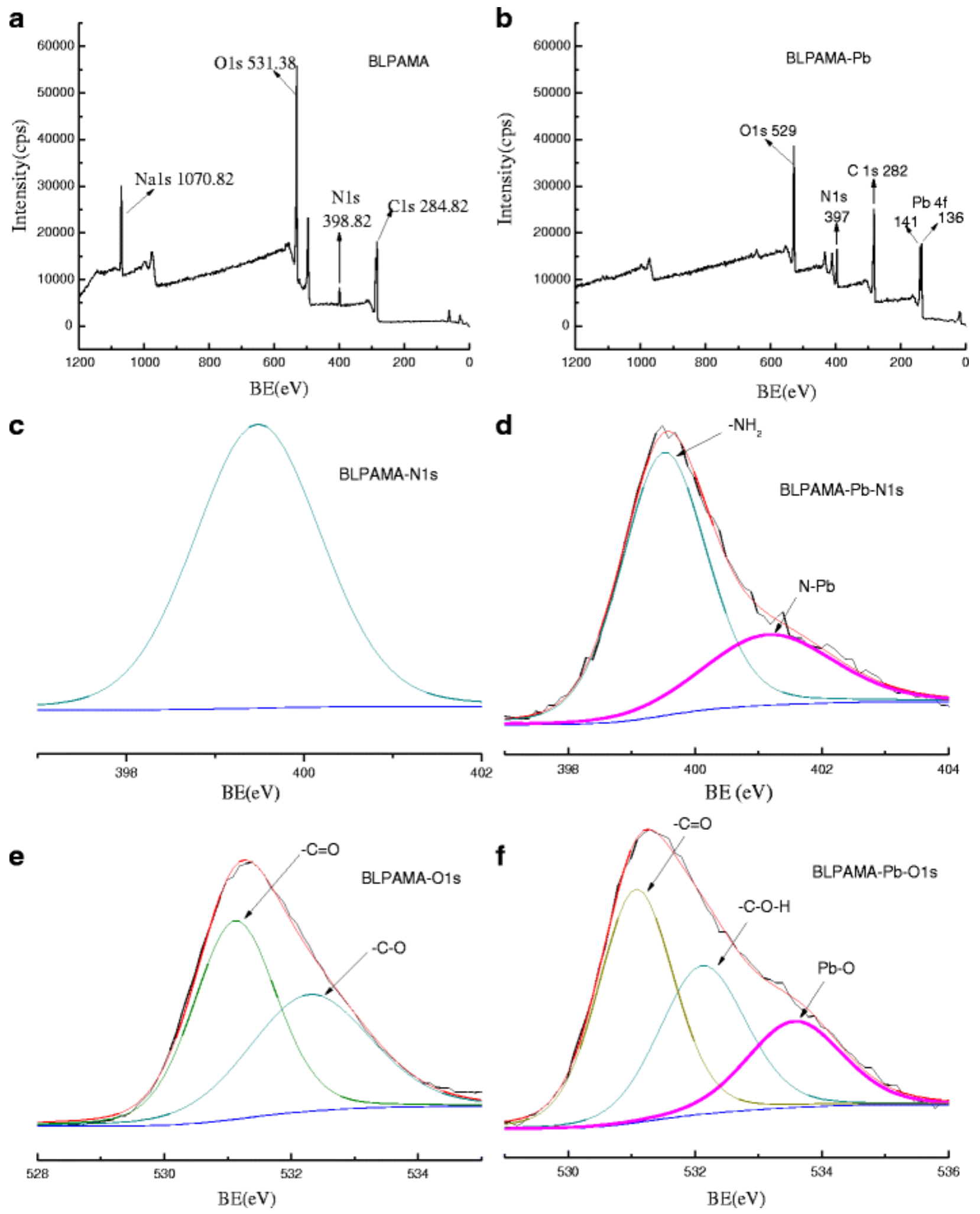

Figure 11. The typical XPS wide scan spectra of BLPAMA before (a) and after (b) $\mathrm{Pb}^{2+}$ adsorption, N $1 \mathrm{~s}$ spectra of BLPAMA before (c) and after (d) $\mathrm{Pb}^{2+}$ adsorption, O1s 
spectra of BLPAMA before (e) and after (f) $\mathrm{Pb}^{2+}$ adsorption [93]. Reprinted with permission. [93] Copyright 2014 Springer.

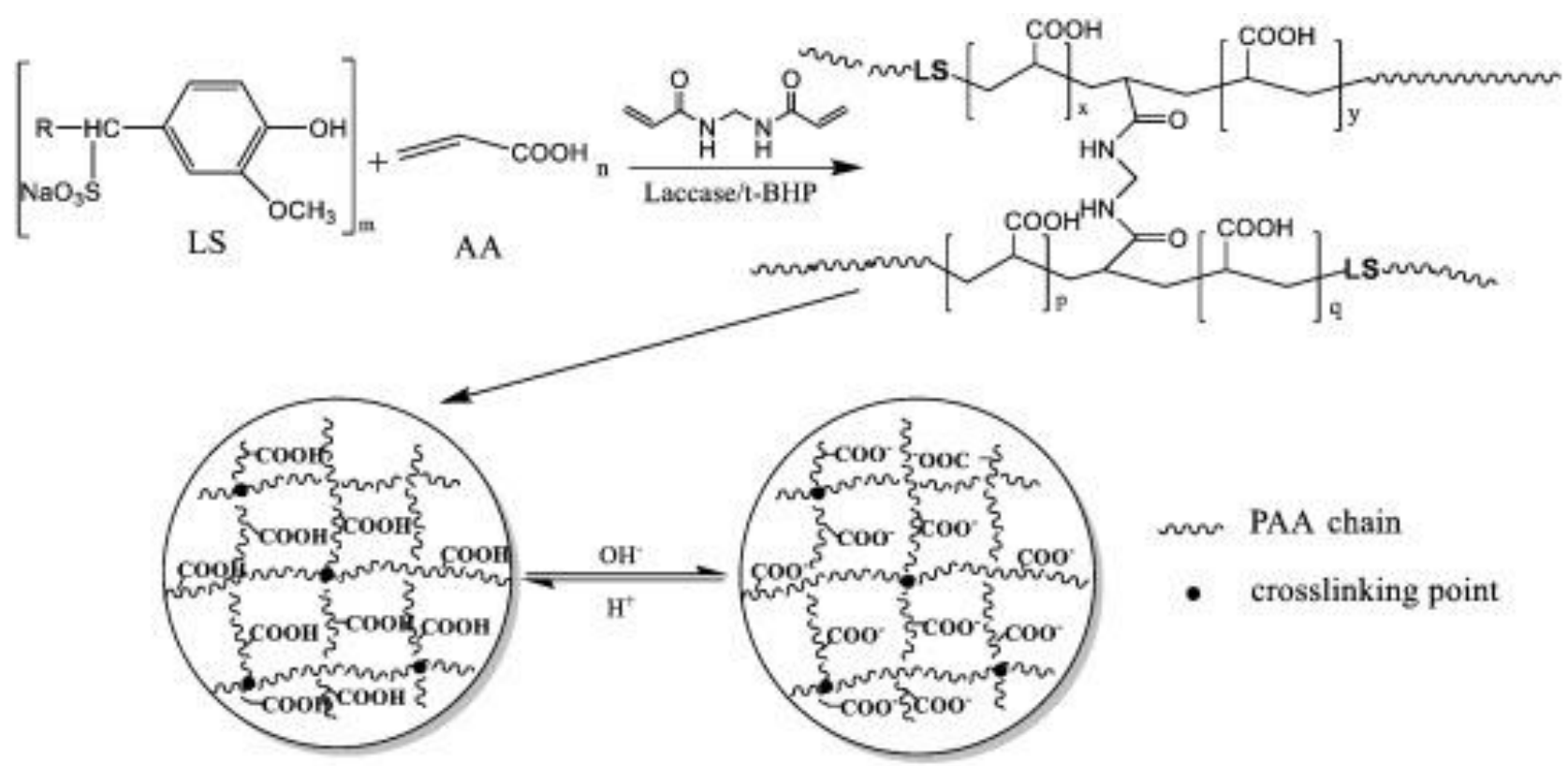

Figure 12. Proposed schematic for synthesis of LS-g-AA hydrogels. [95]. Reprinted with permission. [95] Copyright 2016 Elsevier. 


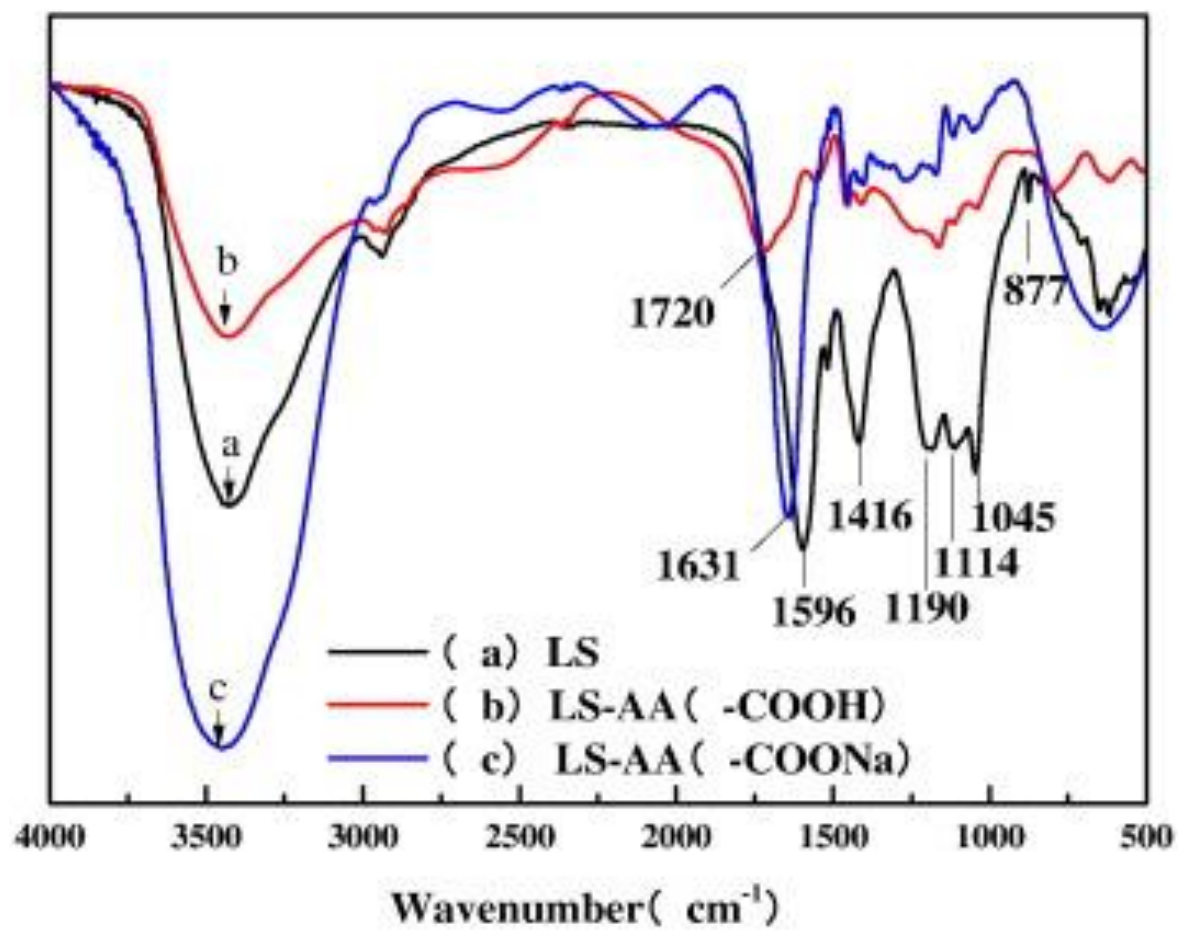

Figure 13. FT-IR spectra of LS (a), LS-g-AA (-COOH) hydrogels (b) and LS-g-AA (-COONa) hydrogels (c). [95]. Reprinted with permission. [95] Copyright 2016 Elsevier. 


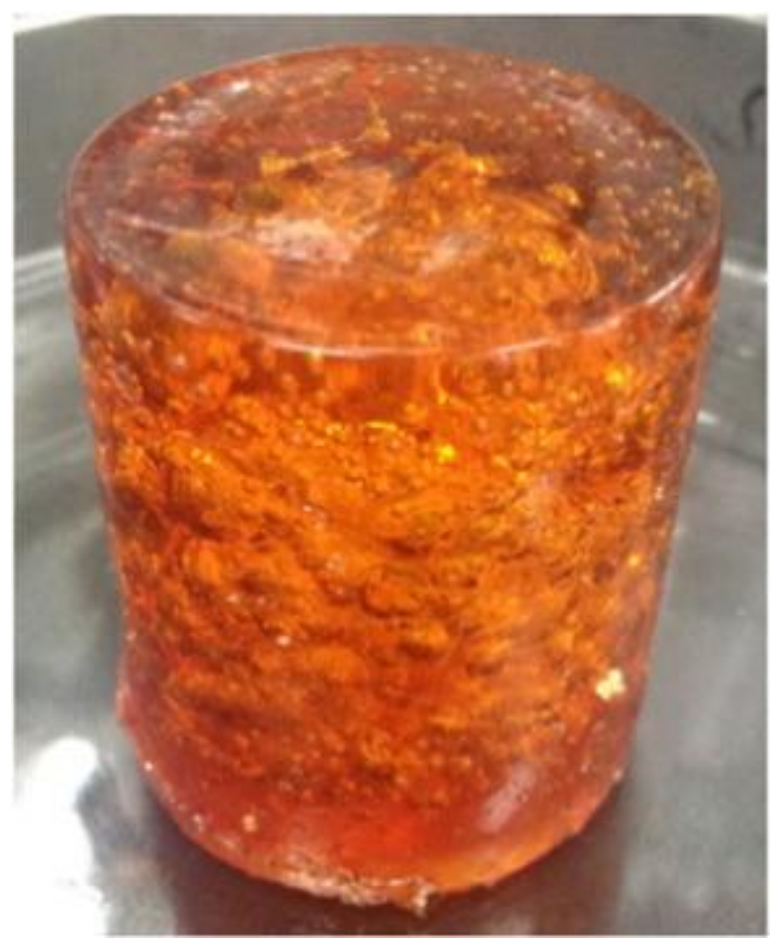

Figure 14. Photograph of LS-g-AA hydrogels in the cylindrical mold [95]. Reprinted with permission. [95] Copyright 2016 Elsevier. 
First step

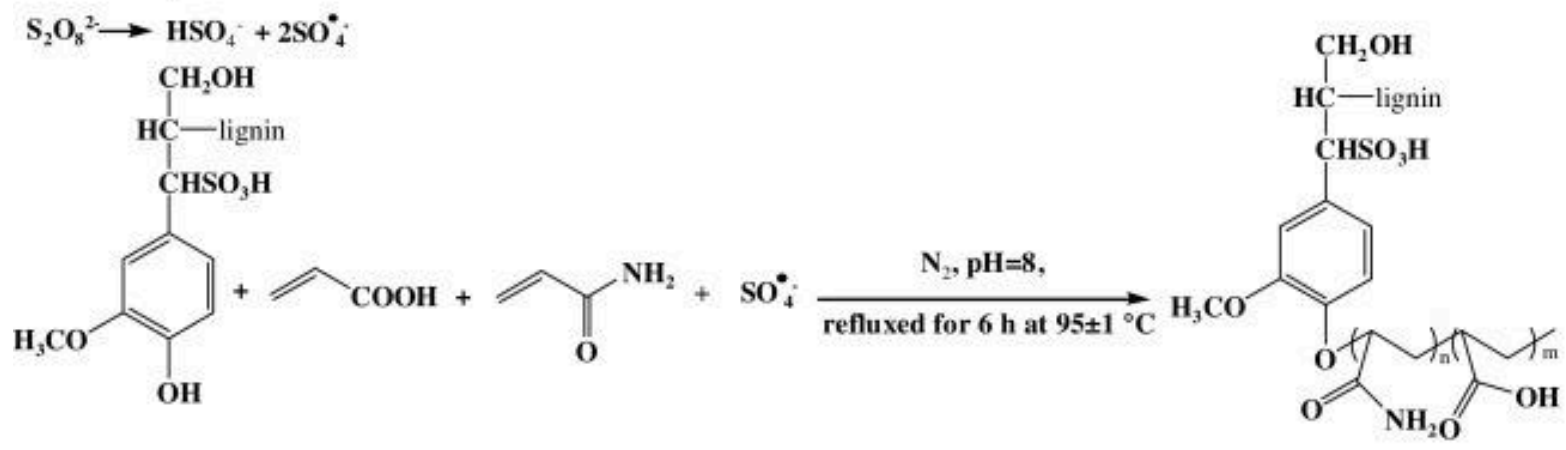

second step

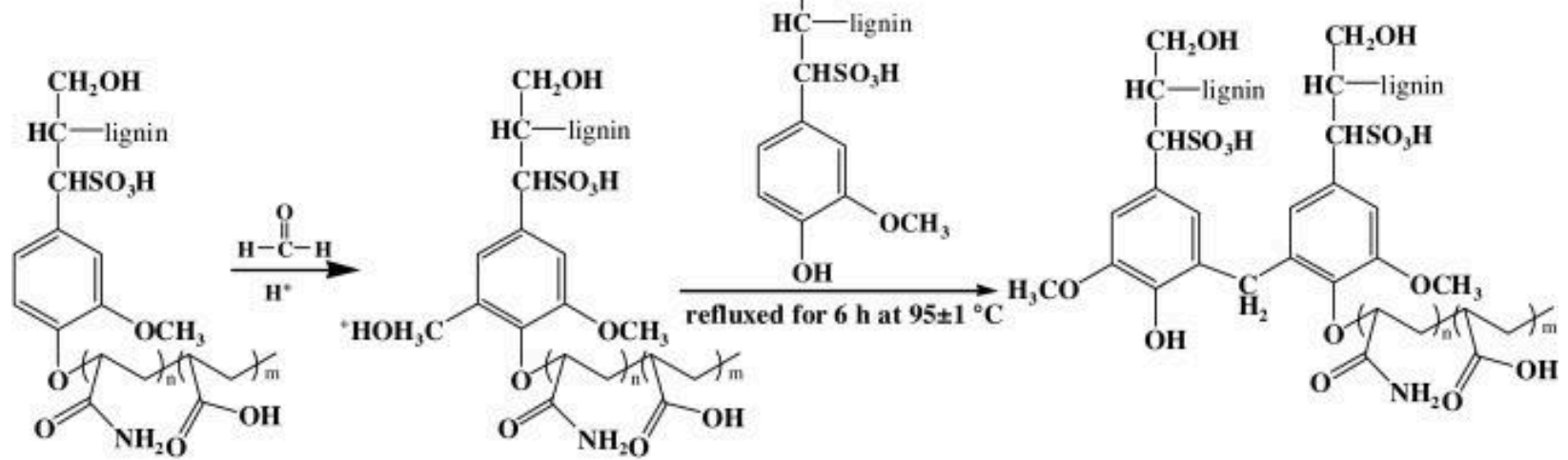

Figure 15. Proposed schematic of the structure unit of the LSMMs. [96]. Reprinted with permission. [96] Copyright 2016 Elsevier. 

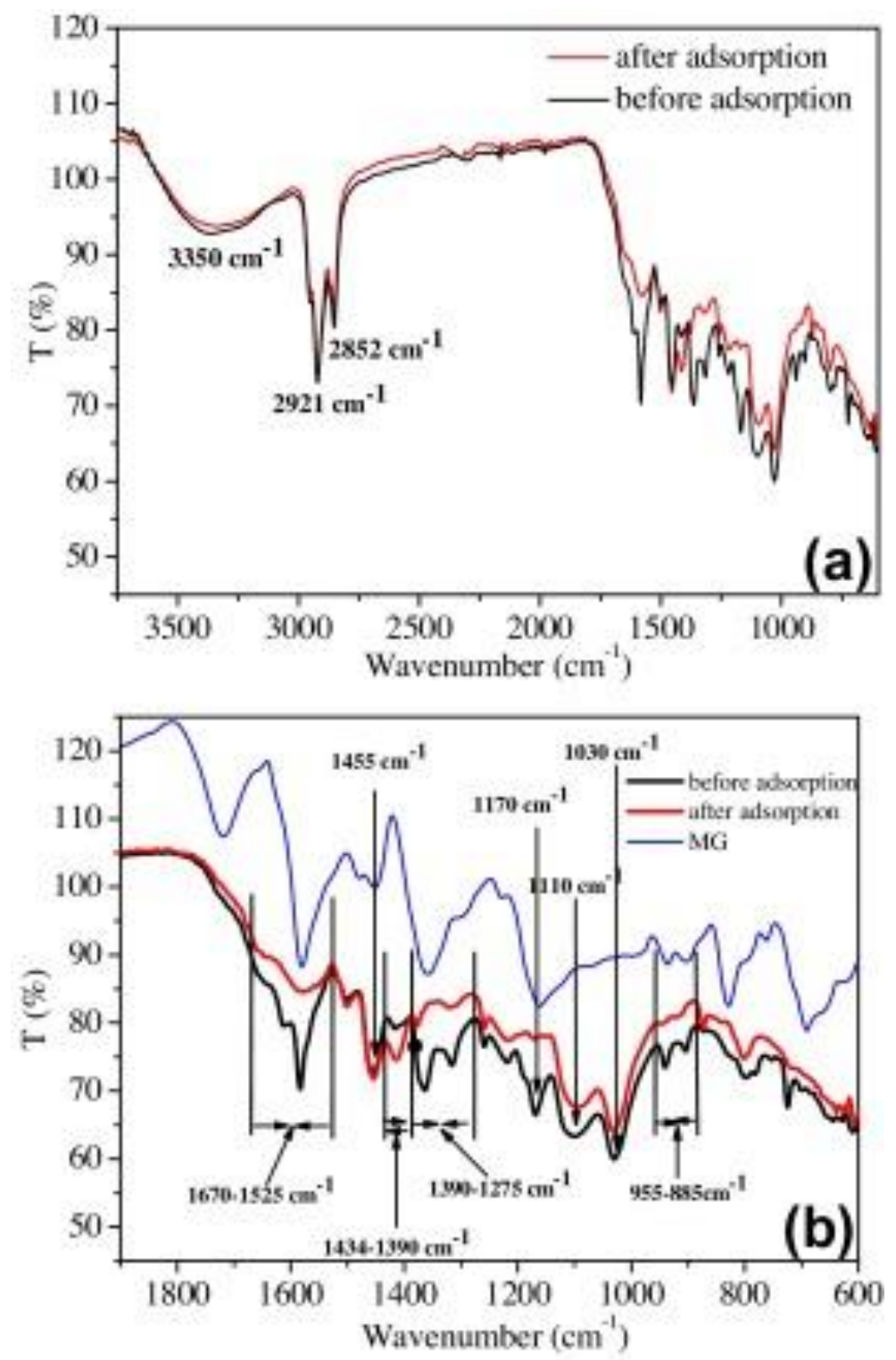

Figure 16. FT-IR spectra of the LSMMs before (black) and after (red) adsorbing MG (blue) [96]. Reprinted with permission. [96] Copyright 2016 Elsevier. 

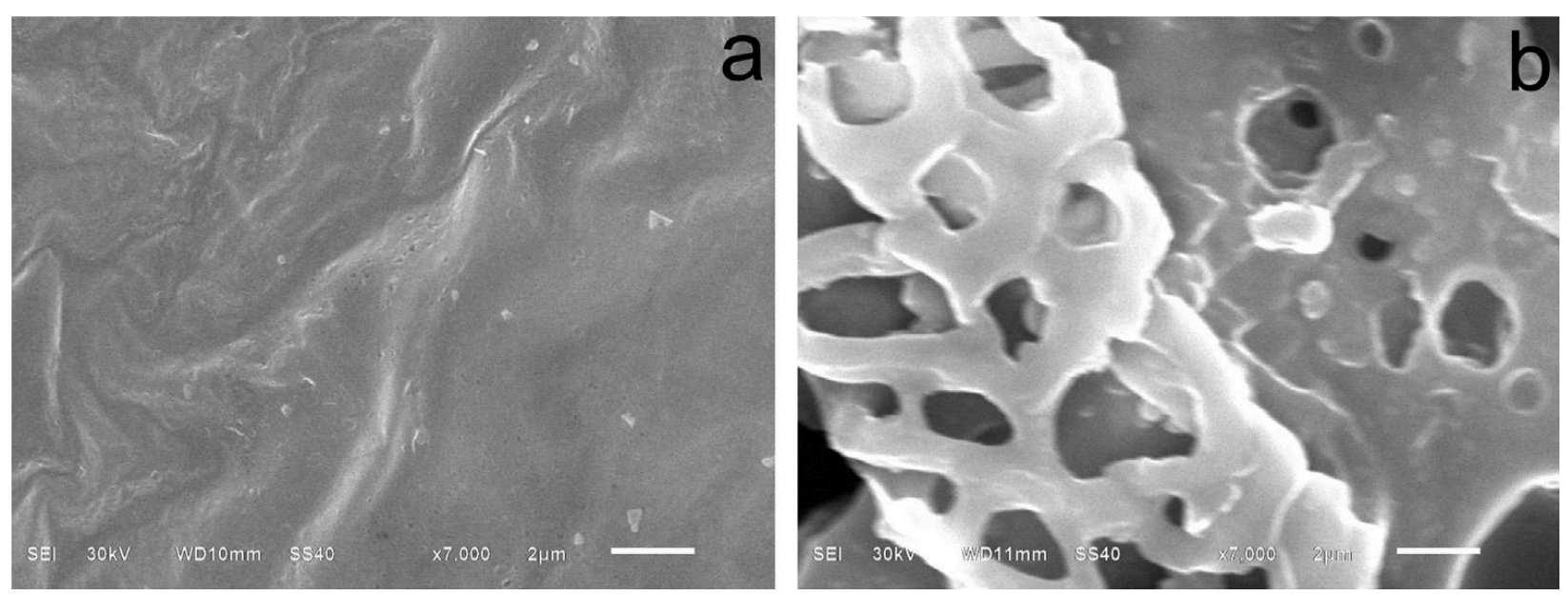

Figure 17. SEM morphology of (a) lignin sulfonate and (b) lignin sulfonate-g-poly (acrylic acid-r-acrylamide) [96]. Reprinted with permission. [96] Copyright 2016 Elsevier.
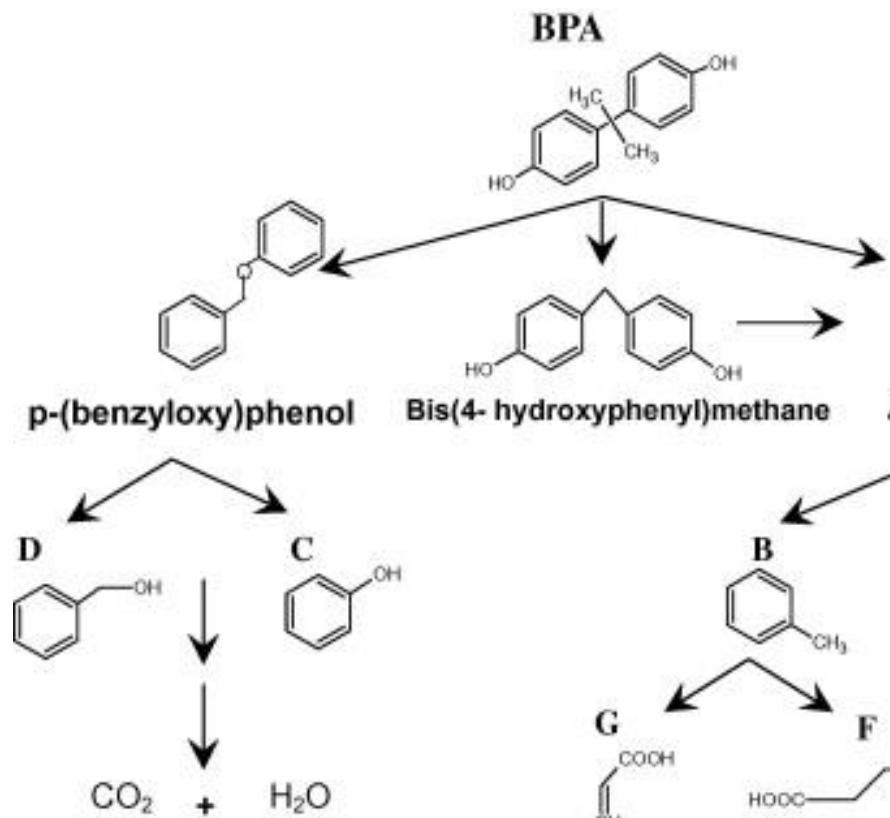

Bis(4- hydroxyphenyl)methane
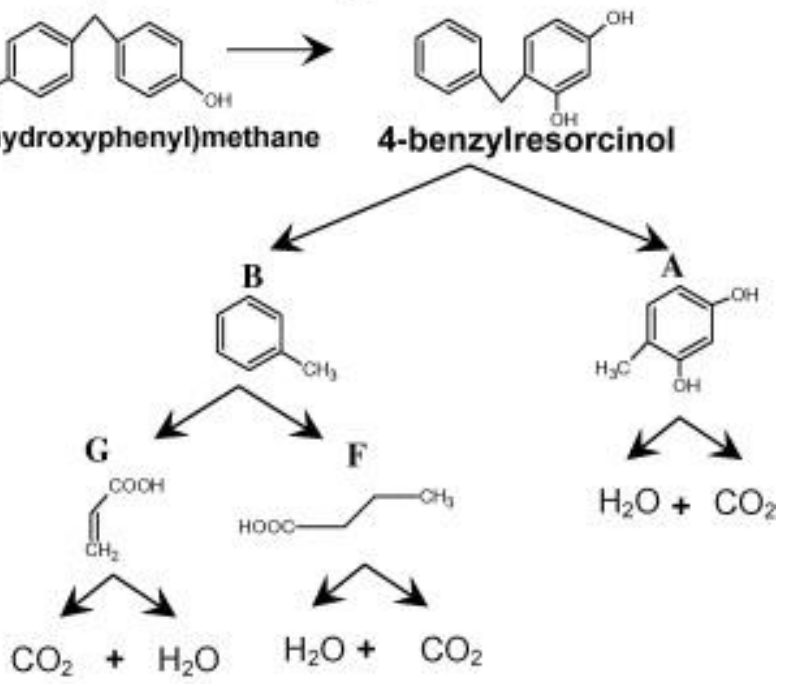
Figure 18. Possible pathways of degradation of bisphenol A. [99]. Reprinted with permission. [99] Copyright 2016 Elsevier.

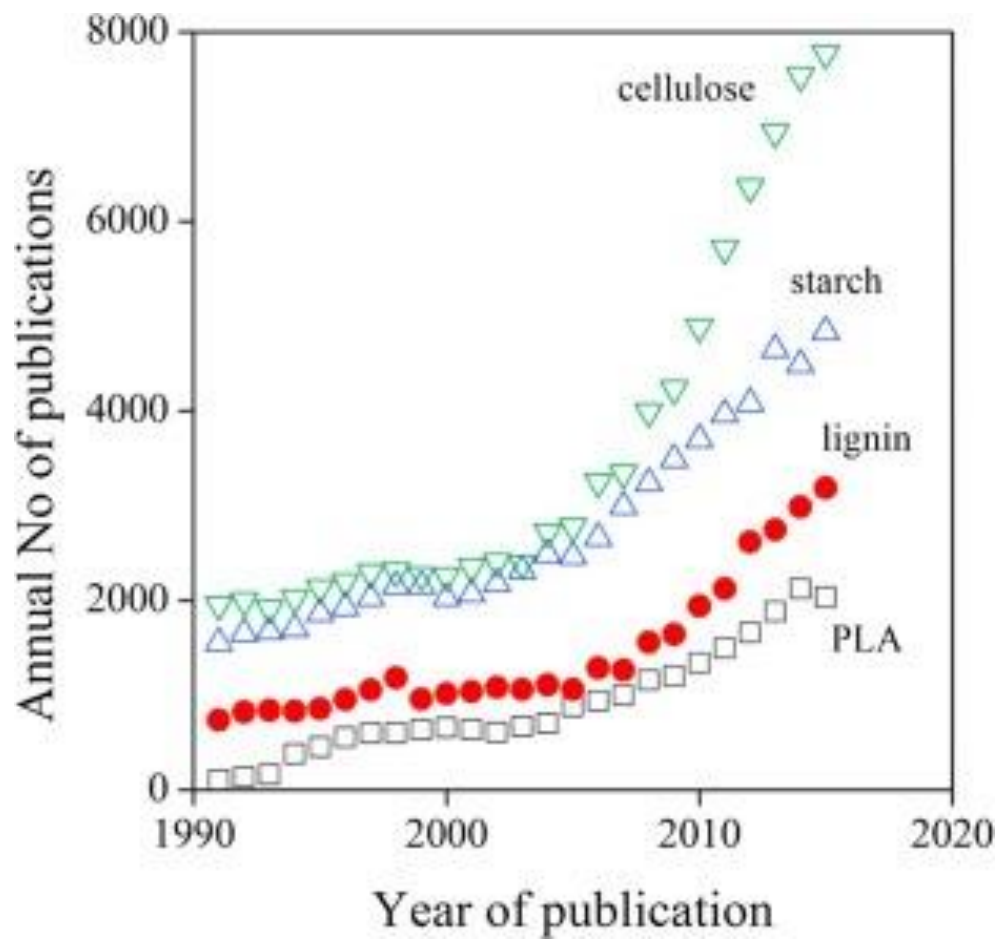

Figure 19. Progress in production of publications [53] on ( $\square) \operatorname{PLA},(\bullet)$ lignin, $(\Delta) \operatorname{starch},(\nabla)$ cellulose [53]. Reprinted with permission. [53] Copyright 2017 Elsevier. 
Table 1. Various lignin based materials utilized for water treatment.

\begin{tabular}{ccc}
\hline Lignin Based Material & Pollutant & Reference \\
Lignosulfonate based graphene & $\mathrm{Pb}^{2+}$ & {$[88]$} \\
hignin grafted polyacrylic & $\mathrm{Pb}^{2+}$ & {$[89]$} \\
hydrogel & & {$[90]$} \\
cellulose-lignin composite & $\mathrm{Pb}^{2+}$ & {$[91]$} \\
hydrogel & $\mathrm{Cr}^{6+}$ & {$[92]$} \\
Silk sericin and lignin blend & & {$[93]$} \\
adsorbent & $\mathrm{As}^{5+}$ and $\mathrm{Cr}^{6+}$ & {$[96]$} \\
Hemicelluloses based hydrogels & $\mathrm{Pb}^{2+}$ & {$[95]$} \\
Bentonite/sodium & & \\
Lignosulfonate/acrylamide/maleic \\
anhydride hydrogel
\end{tabular}




\begin{tabular}{cc}
\hline hydrogel & \\
Kraft lignin- $N$-isopropyl & Methylene blue \\
acrylamide hydrogel & \\
Manganese peroxidase/lignin & Bisphenol A \\
peroxidase/laccase/polyacrylamide/ & \\
pectin hydrogel
\end{tabular}


2017-08-12

\section{Progress in lignin hydrogels and} nanocomposites for water purification:

\section{Future perspectives}

Thakur, Sourbh

Elsevier

Thakur S, Govender PP, Mamo MA, et al., (2017) Progress in lignin hydrogels and nanocomposites for water purification: Future perspectives, Vacuum, Volume 146, December 2017, pp. 342-355

https://doi.org/10.1016/j.vacuum.2017.08.011

Downloaded from Cranfield Library Services E-Repository 